\title{
Insights into the role of immunosenescence during varicella zoster virus infection (shingles) in the aging cell model
}

\author{
Ji-Ae Kim ${ }^{1, *}$, Seul-Ki Park1,*, Mukesh Kumar², Chan-Hee Lee ${ }^{3}$ and Ok Sarah Shin ${ }^{1,4}$ \\ ${ }^{1}$ Department of Biomedical Sciences, College of Medicine, Korea University, Seoul, Republic of Korea \\ ${ }^{2}$ Department of Tropical Medicine, Medical Microbiology and Pharmacology, Pacific Center for Emerging Infectious Diseases \\ Research, John A. Burns School of Medicine, University of Hawaii at Manoa, Honolulu, HI, USA \\ ${ }^{3}$ Department of Microbiology, Chungbuk National University, Cheongju, Republic of Korea \\ ${ }^{4}$ Department of Microbiology, College of Medicine, Korea University, Seoul, Republic of Korea \\ ${ }^{*}$ These authors have contributed equally to this work \\ Correspondence to: Ok Sarah Shin, email: oshin@korea.ac.kr
}

Keywords: immunosenescence, progeria, VZV, STING, shingles, Gerotarget

Received: August 29, $2015 \quad$ Accepted: September 25, $2015 \quad$ Published: October 14, 2015

This is an open-access article distributed under the terms of the Creative Commons Attribution License, which permits unrestricted use, distribution, and reproduction in any medium, provided the original author and source are credited.

\section{ABSTRACT}

Varicella zoster virus (VZV) is the etiological agent of shingles, a painful skin rash that affects a significant proportion of the elderly population. In the present study, we used two aging cell models, Hutchinson-Gilford progeria syndrome (HGPS) fibroblasts and stress or replicative senescence-induced normal human dermal fibroblasts (NHDFs), to investigate age-associated susceptibility to VZV infection. VZV infectivity titers were significantly associated with donor age in HGPS fibroblasts and senescence induction in NHDFs. High throughput RNA-sequencing (RNA-seq) analysis was performed to assess global and dynamic changes in the host transcriptomes of VZV-infected aging cells. Analysis of differentially expressed genes (DEGs) indicated that VZV infection in aged HGPS fibroblasts resembled that in senescent NHDFs, particularly in terms of genes associated with pattern recognition receptors in virus sensing network, providing novel insights into the mechanisms of senescenceassociated susceptibility to VZV infection. Additionally, we identified stimulator of interferon genes (STING) as a potential VZV sensing receptor. Knockdown of STING expression resulted in increased viral replication in primary fibroblasts, whereas STING overexpression led to suppression of VZV plaque formation. In conclusion, our findings highlight the important role of immunosenescence following VZV infection and provide significant insights into the mechanisms underlying cellular sensing of VZV infection and the induction of immune responses in aged skin cells.

\section{INTRODUCTION}

Varicella zoster virus (VZV), a member of the Alphaherpesvirinae subfamily, causes chickenpox (varicella) upon primary infection. Reactivation of VZV from a neuronal latent state results in shingles (herpes zoster) [1]. VZV tropism is mainly associated with the skin and mucosa. In chickenpox and shingles, VZV replication in the epidermal layer of the skin results in the formation of large polykaryocytes and the development of blisters containing infectious virus. Elderly individuals exhibit increased susceptibility to shingles. The mechanisms underlying VZV susceptibility among the aged are currently unclear; however, there is some evidence to suggest that aging is correlated with dysfunctional immune cell-mediated virus clearance [2].

The efficacy and effectiveness of vaccines against VZV decrease with the age of the individual, because of the negative impact of aging on the immune system and its ability to function $[3,4]$. Aging is thought to be promoted by cellular senescence, with senescent cells accumulating in the tissues and organs of aging individuals [5]. The term 'immunosenescence' has been used to describe the gradual deterioration of the immune system during aging. 
Immunosenescence appears to result in an increased susceptibility to infectious diseases and inflammationrelated pathological conditions [6]. In the elderly, increased susceptibility to herpes zoster and decreased vaccine efficacy are attributed to immunosenescence [7]. The roles and mechanisms of immunosenescence in the elderly during VZV infection are yet to be fully elucidated.

Hutchinson-Gilford progeria syndrome (HGPS) is a rare genetic condition. Affected individuals have an average life span of 13 years [8]. Recent studies demonstrate that, similar to certain aspects of premature aging [9], the signaling pathway activation state in cells derived from chronologically young patients with HGPS strongly resembles that in cells from normal middleaged and elderly individuals [10]. A silent point mutation (C1824T) in the $L M N A$ gene results in the production of a truncated form of the lamin $\mathrm{A} / \mathrm{C}$ protein, known as progerin, which accounts for the accelerated aging phenotype in HGPS. Progerin induces nuclear blebbing in HGPS cells grown in culture [11]. Specifically, primary fibroblasts from HGPS patients exhibit characteristic nuclear blebbing and punctate accumulation of progerin, as well as a reduced growth rate [12]. Cellular aging in HGPS fibroblast cultures is characterized by an initial period of hyperproliferation, followed by a rapid loss in the number of proliferating cells after several passages [13]. The susceptibility of aging progeria fibroblasts to viruses is yet to be examined.

An improved understanding of the changes underlying the progression of senescence, and of the role(s) of senescence during infection, may enable the development of therapeutic strategies for age-related pathologies and infectious diseases [14]. Recently, high throughput RNA sequencing (RNA-seq) technology has been used to profile host transcriptomes during viral infections and diseases [15-20]. The application of RNAseq technology is potentially very useful for elucidation of the dynamics of the pathogen genome and the systemic changes in host gene expression in response to infection. This would enable the study of mechanisms underlying host susceptibility to viral pathogens during pathogenesis.

In the present study, we sought to characterize VZV replication efficiency in non-senescent and senescent fibroblasts. Additionally, we attempted to examine cell type- and age-specific mRNA profiles, in order to investigate the role and mechanisms of senescence during VZV replication, as well as the host response during VZV infection, in human primary fibroblasts. In addition, we used two models of aging, HGPS fibroblasts and replicative senescence-induced normal human dermal fibroblasts (NHDFs), to investigate age-associated susceptibility to VZV infection.

\section{RESULTS}

\section{Characteristics of VZV infection in HGPS cells}

Progeria is a form of accelerated aging, and aged progeria fibroblasts exhibit cellular senescence [21]. Therefore, we assessed the levels of senescence in progeria fibroblasts. HGPS cells isolated from 3 (HG3)-, 5 (HG5)-, and 8 (HG8) -year-old patients were cultured and used in subsequent experiments. Senescence-associated $\beta$-galactosidase (SA- $\beta$-Gal) staining is commonly used to evaluate senescence [22]. We observed an increase in the numbers of SA- $\beta$-Gal-positive cells with increasing age of HGPS fibroblasts (Figure 1A). The levels of progerin and lamin A/C in HGPS and control fibroblasts were assessed using western blotting (Figure 1B). All HGPS fibroblasts expressed lamin $\mathrm{A} / \mathrm{C}$ as well as progerin; however, progerin was not detected in the control fibroblasts. The nuclei of the control fibroblasts were round and mostly regular in size and shape. In contrast, HGPS fibroblast nuclei were more variable in size, with nuclear envelopes appearing to "bleb" near the cytoplasm, consistent with previous reports (Figure 1C) [13]. In particular, we found that the cellular growth kinetics of HG8 cells were significantly slower than those of HG3 or HG5 cells. Therefore, progeria cells at low passage $(<20)$ were used for all experiments.

Next, we investigated whether aged HGPS fibroblasts were more susceptible to VZV infection. HG3, HG5, and HG8 cell cultures were infected with mock or VZV, a clinical viral strain isolated from a patient with shingles [23], at a multiplicity of infection (MOI) of 0.001 . Plaque assays were performed to measure viral titers. Plaque formation was significantly higher for HG5 cultures than for HG3 and HG8 cultures (Figure 1D). Consistent with these results, quantitative real-time reverse transcription polymerase chain reaction (qRT-PCR) assays revealed that the expression of the VZV gene open reading frame 4 (ORF4) was approximately 3 -fold higher in HG5 cultures than in HG3 and HG8 cultures (Figure 1E). Given that glycoprotein $\mathrm{E}$ ( $\mathrm{gE}$ ) of VZV, encoded by ORF68, is the most abundant VZV glycoprotein [1], we measured $\mathrm{gE}$ protein levels in VZV-infected HGPS cells. At 24 h postinfection (hpi), gE levels were highest in HG5 cultures compared with HG3 or HG8 cultures. The expression level of gE in VZV-infected HG3 cultures peaked at 24$48 \mathrm{hpi}$, and was found to decrease dramatically at $72 \mathrm{hpi}$. The HG8 cultures exhibited lowest levels of VZV gE at all time points (Figure 1F). Based on these results, we speculated that progeria fibroblasts are susceptible to VZV infection, and that viral replication efficiency is affected by the age of cells. 
Table 1: Top 10 Up-regulated DEG genes from VZV-infected progeria and NHDF cells

\begin{tabular}{|c|c|c|c|c|c|c|c|c|c|}
\hline \multirow[t]{3}{*}{ Rank } & \multicolumn{9}{|c|}{ Progeria } \\
\hline & \multicolumn{3}{|c|}{ HG3 } & \multicolumn{3}{|c|}{ HG5 } & \multicolumn{3}{|c|}{ HG8 } \\
\hline & Genes & $\begin{array}{c}\text { Fold } \\
\text { change }\end{array}$ & $\mathrm{p}$ value & Genes & $\begin{array}{c}\text { Fold } \\
\text { change }\end{array}$ & $\mathrm{p}$ value & Genes & $\begin{array}{c}\text { Fold } \\
\text { change }\end{array}$ & $\mathrm{p}$ value \\
\hline 1. & RPS4Y1 & 208.9535 & $<0.0001$ & CSF3 & 285.0072 & $<0.0001$ & $\mathrm{C} 2 \mathrm{CD} 4 \mathrm{~A}$ & 296.1744 & $<0.0001$ \\
\hline 2. & FAM19A3 & 168.9624 & $<0.0001$ & RPS4Y1 & 243.2414 & $<0.0001$ & $\begin{array}{c}\text { CTD- } \\
2303 \mathrm{H} 24.2\end{array}$ & 234.0324 & $<0.0001$ \\
\hline 3. & $\begin{array}{l}\text { OSTN- } \\
\text { AS1 }\end{array}$ & 168.9624 & $<0.0001$ & AC003092.1 & 168.0631 & $<0.0001$ & PTGDR & 148.5872 & $<0.0001$ \\
\hline 4. & DHRS9 & 104.9767 & 0.0014 & DDX3Y( & 109.591 & $<0.0001$ & EHF & 133.0517 & 0.00012 \\
\hline 5. & GIPC2 & 96.97853 & 0.0024 & FAM213A & 101.2378 & 0.0014 & GBP6 & 117.5162 & 0.00031 \\
\hline 6. & $\begin{array}{c}\text { RP11- } \\
114 \mathrm{H} 23.2 \\
\end{array}$ & 88.98032 & 0.0041 & NLRP3 & 101.2378 & 0.0014 & MIR125B1 & 117.5162 & 0.00031 \\
\hline 7. & $\begin{array}{c}\text { RP3- } \\
\text { 393E18.2 } \\
\end{array}$ & 80.98211 & 0.0041 & IL24 & 94.47401 & $<0.0001$ & TBX5 & 109.7485 & 0.00051 \\
\hline 8. & $\begin{array}{c}\text { RP11- } \\
\text { 753N8.1 }\end{array}$ & 80.98211 & 0.0072 & $\begin{array}{c}\text { BTBD11 } \\
\text { (BTB (POZ) }\end{array}$ & 92.88468 & 0.0024 & $\begin{array}{c}\text { RP3- } \\
465 \mathrm{~N} 24.5 \\
\end{array}$ & 109.7485 & 0.00051 \\
\hline 9. & ASB2 & 72.9839 & 0.0072 & TRBC2 & 84.53153 & 0.0041 & RDH8 & 101.9807 & 0.00085 \\
\hline 10. & USP9Y & 72.9839 & 0.0072 & $\begin{array}{c}\text { RP3- } \\
\text { 393E18.2 } \\
\end{array}$ & 84.53153 & 0.0041 & $\begin{array}{c}\text { RP11- } \\
211 \mathrm{G} 3.2 \\
\end{array}$ & 101.9807 & 0.00085 \\
\hline
\end{tabular}

\begin{tabular}{|c|c|c|c|c|c|c|}
\hline \multirow{3}{*}{ Rank } & \multicolumn{6}{|c|}{ NHDF } \\
\hline & \multicolumn{3}{|c|}{ Non-senescent NHDF } & \multicolumn{3}{|c|}{ Senescent NHDF } \\
\hline & Genes & Fold change & $p$ Value & Genes & Fold change & $p$ Value \\
\hline 1. & CXCL3 & 2244.541 & $<0.0001$ & CXCL8 & 4004.224 & $<0.0001$ \\
\hline 2. & CXCL8 & 1870.27 & $<0.0001$ & CCL7 & 1776.975 & $<0.0001$ \\
\hline 3. & MIR146A & 559.8892 & $<0.0001$ & CXCL6 & 1511.021 & $<0.0001$ \\
\hline 4. & IL-1B & 496.0161 & $<0.0001$ & CXCL1 & 774.4706 & $<0.0001$ \\
\hline 5. & CXCL1 & 474.5578 & $<0.0001$ & CCL20 & 663.9217 & $<0.0001$ \\
\hline 6. & IFI44L & 388.0203 & $<0.0001$ & CSF2 & 508.4215 & $<0.0001$ \\
\hline 7. & RPS4Y1 & 336.3335 & $<0.0001$ & MIR146A & 475.6846 & $<0.0001$ \\
\hline 8. & CSF2 & 304.397 & $<0.0001$ & RPS4Y1 & 385.6582 & $<0.0001$ \\
\hline 9. & CXCL6 & 298.7515 & $<0.0001$ & PTHLH & 312.0003 & $<0.0001$ \\
\hline 10. & OASL & 287.0317 & $<0.0001$ & CXCL2 & 264.4527 & $<0.0001$ \\
\hline
\end{tabular}

\section{Characteristics of the replicative or stress- mediated senescence aging model and VZV replication}

Replicative senescence was first described by Hayflick and Moorhead, who observed that human fibroblasts in culture underwent extensive replication as a consequence of serial passaging [24]. In order to confirm the senescence phenotype during replicative senescence, we compared non-senescent NHDFs at low passage with senescent NHDFs that had been subjected to over 20 passages following infection with VZV. Induction of senescence in high-passaged NHDFs was confirmed, and increased numbers of SA- $\beta$-Gal-positive cells were observed (Figure 2A). Then, we investigated whether the efficacy of VZV replication differed between nonsenescent and senescent cells. Senescent NHDFs exhibited approximately 1.5 -fold higher VZV infectivity titers than non-senescent NHDFs (Figure 2B). Additionally, we determined whether stress-induced senescence modulates VZV replication. Stress-induced senescence induced by $\mathrm{H}_{2} \mathrm{O}_{2}$ treatment of non-senescent cells was confirmed by an increase in the number of SA- $\beta$-Gal-positive cells (Figure 2C). We also measured transcriptional levels of VZV-specific genes 14 (late), and 63 (immediate early) during senescence. The mRNA levels of ORF 14 and 63 were significantly higher in VZV-infected senescent cells than in non-infected non-senescent cells (Figure 2D). Additionally, we found that oxidative stress damage 
due to $\mathrm{H}_{2} \mathrm{O}_{2}$ treatment of non-senescent cells resulted in significant upregulation of VZV gene expression, which
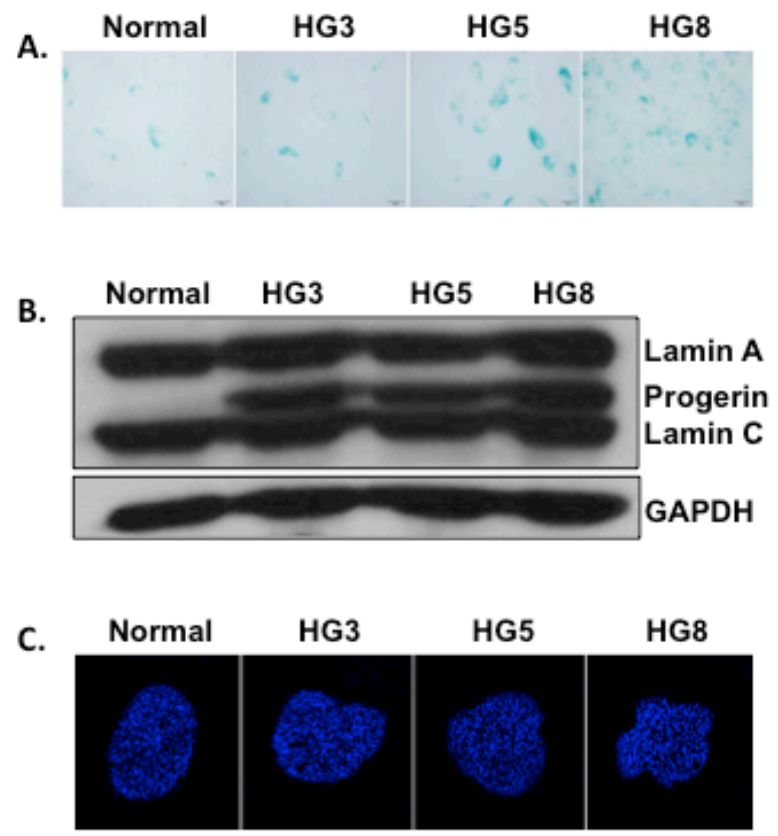

was also observed during senescence-mediated induction of VZV replication.
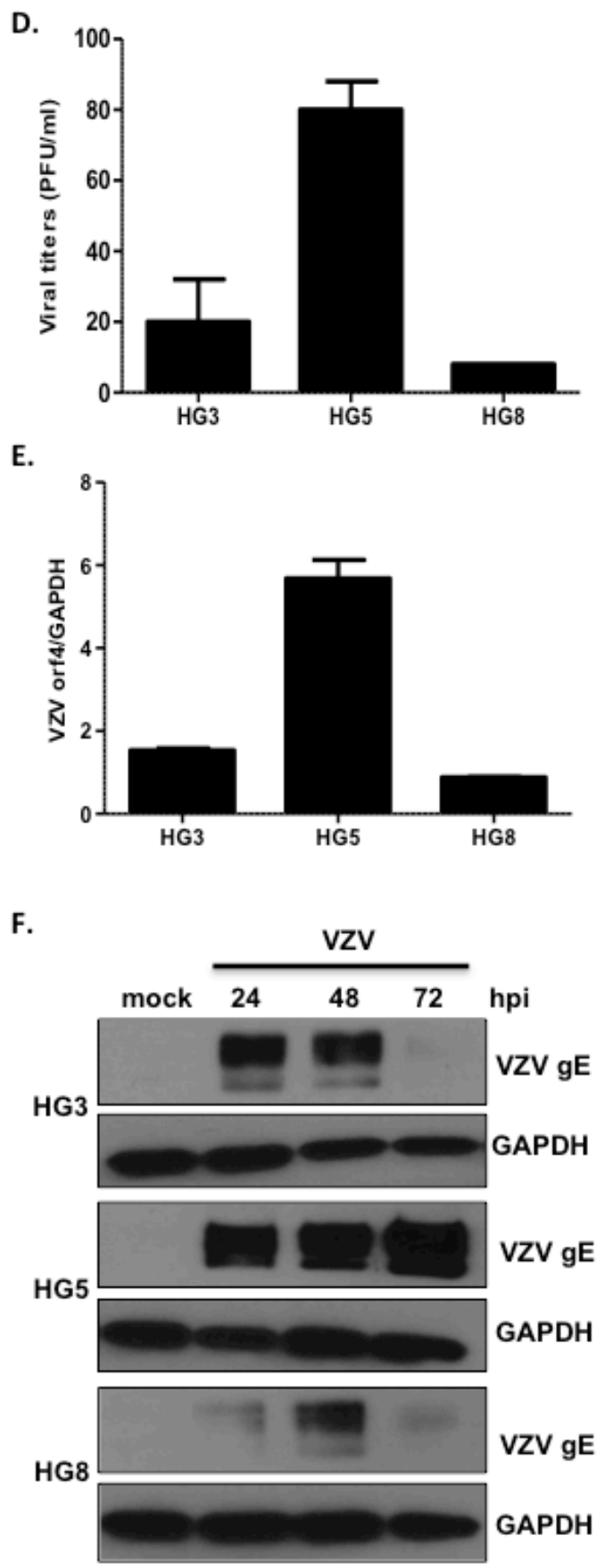

Figure 1: Age-associated changes in viral replication efficiency in HGPS fibroblasts. (A) The extent of senescence-associated $\beta$-galactosidase (SA- $\beta$-Gal) staining increased with increasing age of progeria cells (HGPS cells isolated from 3- (HG3), 5- (HG5), and 8- (HG8) year-old patients). (B) Western blotting analysis of progerin and lamin A/C in progeria cells. Glyceraldehyde 3-phosphate dehydrogenase (GAPDH) was used as a loading control. (C) Progeria cell nuclei were stained with 4,6-diamidino-2-phenylindole (DAPI) and examined by confocal microscopy. Images shown are representative of results from three independent experiments. (D) Plaque assays were used to determine VZV titers in progeria cells. Results are presented as plaque-forming units (PFU)/mL and are the mean $\pm \mathrm{SD}$ from three independent experiments. (E) We used quantitative reverse transcription polymerase chain reaction (qPCR) assays to measure the mRNA levels of VZV open reading frame 4 (ORF4; immediate early gene). Transcript expression levels were calculated in relation to the expression level of GAPDH mRNAs. VZV-infected HG8 cells were arbitrarily set to 1 . We performed qPCR assays in duplicate, with the mean \pm SD from all experiments shown. (F) Cells were infected with mock or VZV at a multiplicity of infection (MOI) of 0.001 for 24,48 , or $72 \mathrm{~h}$, (hpi; hours post infection) and the level of VZV glycoprotein E (gE) protein present was determined by western blotting. 


\section{Analysis of RNA-seq transcriptome data reveals distinct and dynamic changes in aging cells}

Given than HGPS cells mimic the normal aging process at the cellular level and are susceptible to VZV infection, RNA-seq was performed to explore the transcriptome of primary fibroblasts derived from 3-, 5-, and 8-year-old HGPS patients. Primary fibroblasts were infected with mock or VZV for $24 \mathrm{~h}$ and RNA was isolated. More than 206 million 101-bp paired-end reads were generated. Gene expression profiles for mockinfected HG3, HG5, and HG8 cultures were compared with those of VZV-infected cultures in order to identify differentially expressed genes (DEGs) with a fold change of \pm 2 and a $q$-value $<0.05$. We identified 1,809, 2,310, and 3,955 upregulated genes in HG3, HG5, and HG8

A.

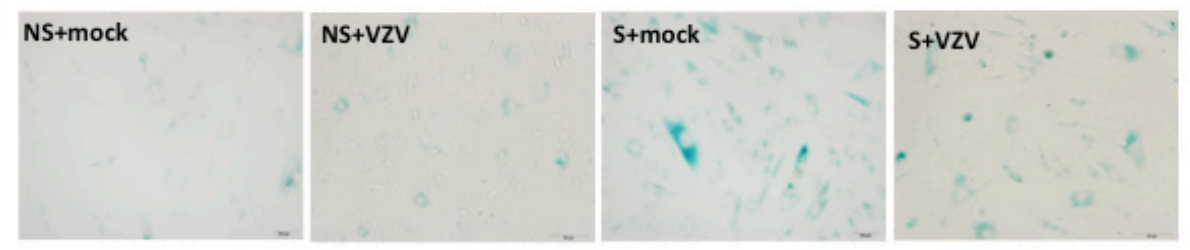

B.

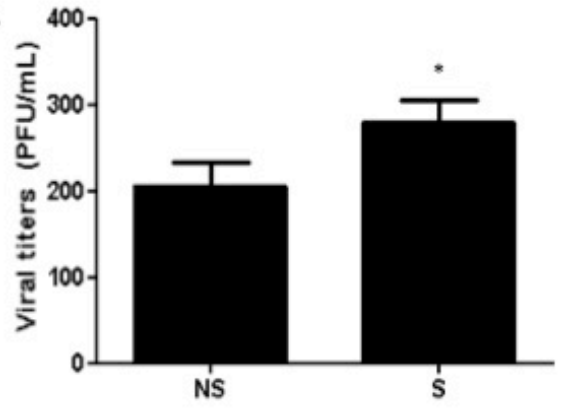

C.
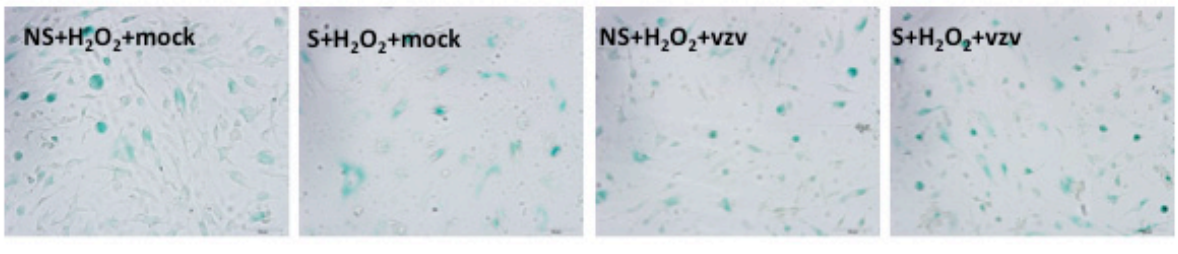

D.
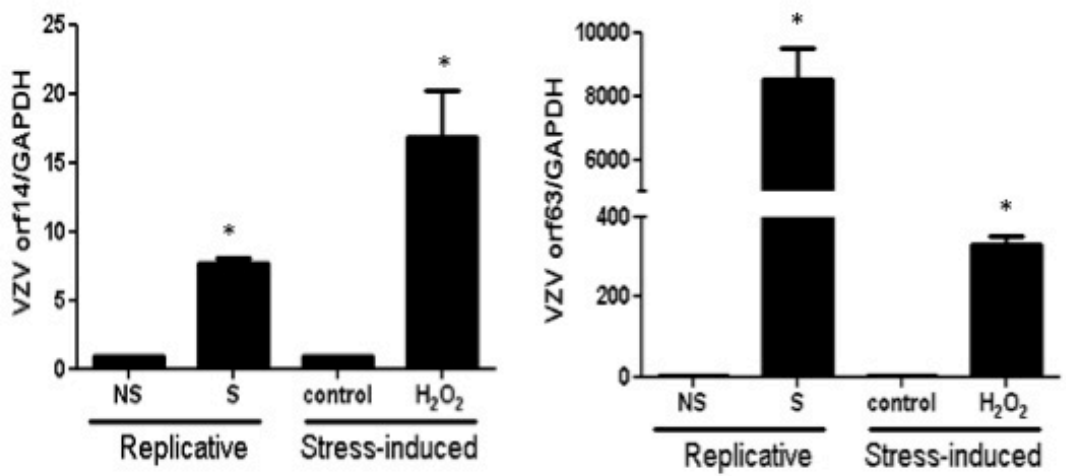

Figure 2: Stress-induced or replicative senescence in normal human dermal fibroblasts (NHDF) affects viral replication. (A) Non-senescent (NS) and senescent (S) NHDFs were infected with VZV at an MOI of 0.001 and senescence-associated $\beta$-galactosidase (SA- $\beta$-Gal) was added. Senescence was induced at high passage NHDFs and confirmed by positive staining. (B) Plaque assays were conducted. Results are presented as PFU $/ \mathrm{mL}$ and are the mean $\pm \mathrm{SD}$ from three independent experiments. ${ }^{*} p<0.05$ vs. VZVinfected NS cells. (C) Stress-induced senescence in hydrogen peroxide $\left(\mathrm{H}_{2} \mathrm{O}_{2}\right)$ treated NS NHDFs was confirmed by senescence-associated $\beta$-galactosidase (SA- $\beta$-Gal) staining. (D) VZV ORF14 (late) and 63 (immediate early) gene expressions were measured by qPCR. Transcript expression levels were calculated in relation to the expression level of GAPDH mRNAs. NS cells that were VZV-infected were arbitrarily set to 1 . We performed qPCR assays in duplicate, with the mean $\pm \mathrm{SD}$ from all experiments shown. ${ }^{*} p<0.05$ vs. mock-infected cells. 


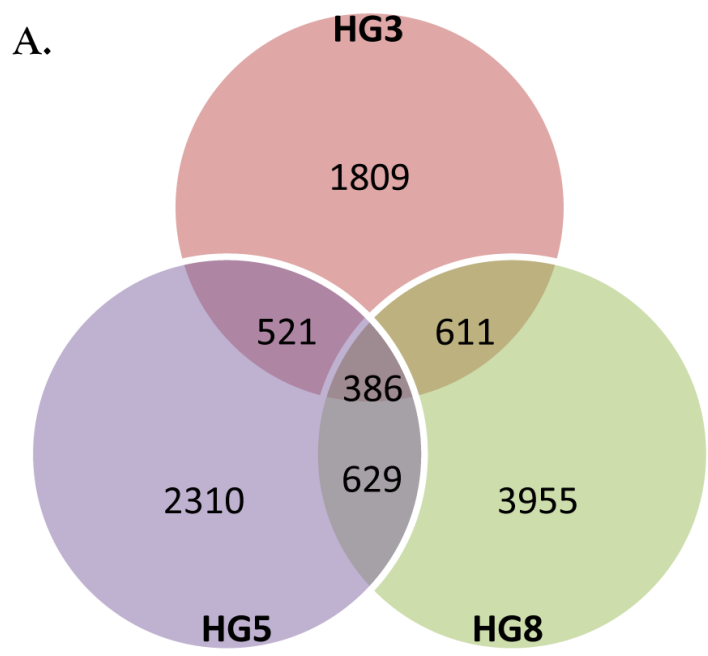

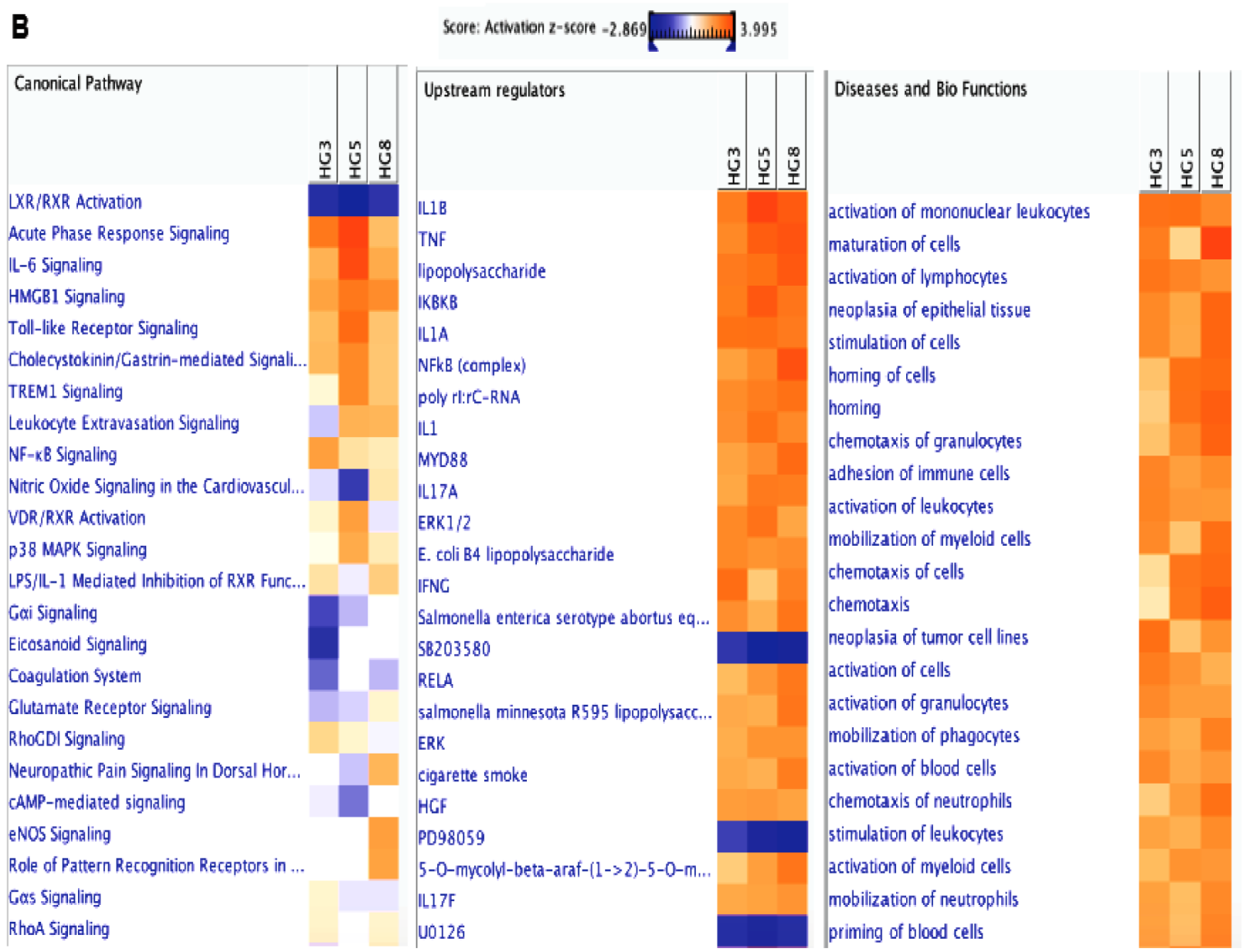

Figure 3: Transcriptome analysis of VZV-infected HGPS cells. RNA-seq analysis was performed with RNA isolated from cells derived from HG3, HG5, and HG8 cultures that were infected with mock or VZV. (A) Venn diagram indicates the number of significant ( $>2$-fold upregulation, FDR, 0.05) DEGs across three key comparisons (HG3, HG8, HG8) and the overlap between each set of genes. (B) Ingenuity Pathway Analysis (IPA) tool was used to generate the list of highest activated networks and genes with their respective scores obtained from IPA and categorized as canonical pathways, upstream regulators and diseases and biofunctions. Networks and genes shaded orange were upregulated, while those in blue were downregulated. Shading intensity indicates the degree that each gene was upregulated or downregulated. Range of activation z-score is also depicted on the figure. 
Table 2: The top 10 enriched KEGG pathways of DEGs in VZV-infected progeria and NHDF cells

\begin{tabular}{|c|c|c|c|c|c|}
\hline \multirow{2}{*}{ Rank } & \multicolumn{3}{|c|}{ Progeria } & \multicolumn{2}{|c|}{ NHDF } \\
\hline & HG3 & HG5 & HG8 & Non-senescent & Senescent \\
\hline 1 & Cell cycle & $\begin{array}{l}\text { Cytokine- } \\
\text { cytokine receptor } \\
\text { interaction }\end{array}$ & $\begin{array}{l}\text { Cytokine- } \\
\text { cytokine receptor } \\
\text { interaction }\end{array}$ & $\begin{array}{l}\text { Cytokine-cytokine } \\
\text { receptor interaction }\end{array}$ & $\begin{array}{l}\text { NOD-like receptor } \\
\text { signaling pathway }\end{array}$ \\
\hline 2 & $\begin{array}{l}\text { NOD-like receptor } \\
\text { signaling pathway }\end{array}$ & $\begin{array}{c}\text { NOD-like } \\
\text { receptor signaling } \\
\text { pathway }\end{array}$ & $\begin{array}{l}\text { Hematopoietic } \\
\text { cell lineage }\end{array}$ & $\begin{array}{l}\text { NOD-like receptor } \\
\text { signaling pathway }\end{array}$ & $\begin{array}{l}\text { Cytokine-cytokine } \\
\text { receptor interaction }\end{array}$ \\
\hline 3 & $\begin{array}{l}\text { Cytokine- } \\
\text { cytokine receptor } \\
\text { interaction }\end{array}$ & $\begin{array}{l}\text { Chemokine } \\
\text { signaling } \\
\text { pathway }\end{array}$ & $\begin{array}{l}\text { NOD-like } \\
\text { receptor } \\
\text { signaling } \\
\text { pathway }\end{array}$ & $\begin{array}{l}\text { Cytosolic DNA- } \\
\text { sensing pathway }\end{array}$ & $\begin{array}{c}\text { Cytosolic DNA-sensing } \\
\text { pathway }\end{array}$ \\
\hline 4 & Oocyte meiosis & $\begin{array}{l}\text { Hematopoietic } \\
\text { cell lineage }\end{array}$ & $\begin{array}{l}\text { Pathways in } \\
\text { cancer }\end{array}$ & $\begin{array}{c}\text { Chemokine signaling } \\
\text { pathway }\end{array}$ & $\begin{array}{c}\text { Chemokine signaling } \\
\text { pathway }\end{array}$ \\
\hline 5 & $\begin{array}{c}\text { Progesterone- } \\
\text { mediated oocyte } \\
\text { maturation }\end{array}$ & $\begin{array}{c}\text { Complement } \\
\text { and coagulation } \\
\text { cascades }\end{array}$ & $\begin{array}{c}\text { Jak-STAT } \\
\text { signaling } \\
\text { pathway } \\
\end{array}$ & $\begin{array}{l}\text { RIG-I-like receptor } \\
\text { signaling pathway }\end{array}$ & $\begin{array}{l}\text { RIG-I-like receptor } \\
\text { signaling pathway }\end{array}$ \\
\hline 6 & $\begin{array}{l}\text { Chemokine } \\
\text { signaling pathway }\end{array}$ & $\begin{array}{l}\text { Jak-STAT } \\
\text { signaling } \\
\text { pathway } \\
\end{array}$ & Apoptosis & Pathways in cancer & $\begin{array}{l}\text { Hematopoietic cell } \\
\text { lineage }\end{array}$ \\
\hline 7 & $\begin{array}{l}\text { Small cell lung } \\
\text { cancer }\end{array}$ & $\begin{array}{l}\text { Pathways in } \\
\text { cancer }\end{array}$ & $\begin{array}{l}\text { Chemokine } \\
\text { signaling } \\
\text { pathway }\end{array}$ & $\begin{array}{l}\text { Arachidonic acid } \\
\text { metabolism }\end{array}$ & Pathways in cancer \\
\hline 8 & $\begin{array}{l}\text { Cytosolic DNA- } \\
\text { sensing pathway }\end{array}$ & & $\begin{array}{l}\text { Calcium } \\
\text { signaling } \\
\text { pathway }\end{array}$ & $\begin{array}{c}\text { Jak-STAT signaling } \\
\text { pathway }\end{array}$ & Bladder cancer \\
\hline 9 & $\begin{array}{l}\text { Toll-like receptor } \\
\text { signaling pathway }\end{array}$ & & Gap junction & Bladder cancer & Purine metabolism \\
\hline 10 & $\begin{array}{l}\text { p53 signaling } \\
\text { pathway }\end{array}$ & & $\begin{array}{l}\text { Arachidonic acid } \\
\text { metabolism }\end{array}$ & $\begin{array}{l}\text { Hematopoietic cell } \\
\text { lineage }\end{array}$ & $\begin{array}{l}\text { Toll-like receptor } \\
\text { signaling pathway }\end{array}$ \\
\hline
\end{tabular}

cultures, respectively. Venn diagrams revealed that the cultures and VZV-infected progeria cells had 386 DEGS in common (Figure 3A). Our results showed that infection with VZV induced distinct cellular gene expression patterns in progeria cells of varying ages. In order to further characterize the DEGs, we focused on the 10 DEGs showing the most marked upregulation. Interestingly, VZV infection in HG5 fibroblasts was associated with the expression of key immune-related genes, such as members of the NOD-like receptor (NLR) family, pyrin domaincontaining 3 (NLRP3) and melanoma differentiationassociated 7 (MDA7)/IL-24, whereas no immune-related genes were found among the top 10 most upregulated DEGs in HG3 and HG8 fibroblasts (Table 1). Host transcriptome data showed a higher number of upregulated DEGs associated with immune function in HG5 cells than in HG3 or HG8 cells, suggesting a strong correlation between viral transcript levels and expression levels of host immune-related genes.

In order to investigate the biological interactions of DEGs and identify important functional networks, the Ingenuity Pathway Analysis (IPA) tool was applied with datasets from altered expression profiles obtained by RNA-seq analysis. Highest activated networks and upstream modulators (high $\mathrm{z}$-score) were identified using IPA. Figure 3B shows separate hierarchical clustering maps depicting highly activated biofunctions, upstream regulators, and canonical pathways after VZV infection in HG3, HG5, and HG8 cells. Acute phase response signaling, Toll-like receptors (TLRs) signaling, interleukin-6 (IL-6) signaling, NF- $\mathrm{kB}$ signaling, and p38 mitogen-activated protein kinase (MAPK) signaling were among the highest activated canonical pathways for HG5 after VZV infection compared with HG3 or HG8 (Figure 3B). Moreover, stimulation, activation, and maturation, along with adherence and migration, were among the most highly activated biofunctions in the progeria cells following VZV infection. Consistent with the increase in senescence levels confirmed by $\beta$-galactosidase staining, HG8 cells revealed a higher z-score (3.992) for cell 
Table 3: The top 10 enriched GO molecular function terms in VZV-infected progeria cells

\begin{tabular}{|c|c|c|c|}
\hline \multirow{2}{*}{ Rank } & \multicolumn{3}{|c|}{ HGPS culture (Go terms, function } \\
\hline & HG3 & HG5 & HG8 \\
\hline 1 & $\begin{array}{c}\text { GO:0008297 single-stranded DNA } \\
\text { specific exodeoxyribonuclease activity }\end{array}$ & $\begin{array}{l}\text { GO:0004666 prostaglandin- } \\
\text { endoperoxide synthase activity }\end{array}$ & $\begin{array}{c}\text { GO:0005220 inositol } \\
\text { 1,4,5-trisphosphate-sensitive } \\
\text { calcium-release channel activity }\end{array}$ \\
\hline 2 & $\begin{array}{c}\text { GO:0016725 oxidoreductase activity, } \\
\text { acting on } \mathrm{CH} \text { or } \mathrm{CH} 2 \text { groups }\end{array}$ & GO:0003680 AT DNA binding & $\begin{array}{l}\text { GO:0004962 endothelin } \\
\quad \text { receptor activity }\end{array}$ \\
\hline 3 & $\begin{array}{l}\text { GO:0016895 } \\
\text { 〜exodeoxyribonuclease activity, } \\
\text { producing 5'-phosphomonoesters }\end{array}$ & $\begin{array}{l}\text { GO:0005030 neurotrophin } \\
\text { receptor activity }\end{array}$ & $\begin{array}{l}\text { GO:0008095 inositol-1,4,5- } \\
\text { trisphosphate receptor activity }\end{array}$ \\
\hline 4 & $\begin{array}{c}\text { GO:0004529 exodeoxyribonuclease } \\
\text { activity }\end{array}$ & $\begin{array}{l}\text { GO:0008330 protein tyrosine/ } \\
\text { threonine phosphatase activity }\end{array}$ & $\begin{array}{c}\text { GO:0015093 ferrous iron } \\
\text { transmembrane transporter } \\
\text { activity }\end{array}$ \\
\hline 5 & GO:0008009 chemokine activity & GO:0043121 neurotrophin binding & $\begin{array}{l}\text { GO:0004924 oncostatin-M } \\
\text { receptor activity }\end{array}$ \\
\hline 6 & $\begin{array}{c}\text { GO:0042379 chemokine receptor } \\
\text { binding }\end{array}$ & $\begin{array}{l}\text { GO:0005138 interleukin-6 } \\
\text { receptor binding }\end{array}$ & $\begin{array}{l}\text { GO:0004571 mannosyl- } \\
\text { oligosaccharide 1,2-alpha- } \\
\text { mannosidase activity }\end{array}$ \\
\hline 7 & $\begin{array}{c}\text { GO:0003777 microtubule motor } \\
\text { activity }\end{array}$ & $\begin{array}{c}\text { GO:0004383 guanylate cyclase } \\
\text { activity }\end{array}$ & $\begin{array}{l}\text { GO:0005138 interleukin-6 } \\
\text { receptor binding }\end{array}$ \\
\hline 8 & GO:0005125 cytokine activity & $\begin{array}{c}\text { GO:0033549 MAP kinase } \\
\text { phosphatase activity }\end{array}$ & $\begin{array}{c}\text { GO:0015924 mannosyl- } \\
\text { oligosaccharide mannosidase } \\
\text { activity }\end{array}$ \\
\hline 9 & GO:0003678 DNA helicase activity & $\begin{array}{c}\text { GO:0017017 MAP kinase } \\
\text { tyrosine/serine/threonine } \\
\text { phosphatase activity }\end{array}$ & $\begin{array}{c}\text { GO:0015085 calcium ion } \\
\text { transmembrane transporter } \\
\text { activity }\end{array}$ \\
\hline 10 & $\begin{array}{c}\text { GO:0003697 single-stranded DNA } \\
\text { binding }\end{array}$ & GO:0008009 chemokine activity & $\begin{array}{c}\text { GO:0015923 mannosidase } \\
\text { activity }\end{array}$ \\
\hline
\end{tabular}

maturation than HG3 or HG5 cells.

We further generated a network map of pattern recognition signaling for $\mathrm{HG} 3$ and $\mathrm{HG} 5$ cultures infected with VZV, using the IPA tool (Figure 4). Notable differences between HG3 and HG5 cultures included differential modulation of TLR receptors, type 1 interferon, and pro-inflammatory cytokine response. Moreover, we also observed activation of NLRP3 (NALP3) in HG5 cultures, whereas the expression of NALP3 was downregulated in HG3. Furthermore, pathway analysis using the Kyoto Encyclopedia of Genes and Genomes (KEGG) revealed that the NLR signaling pathway was the most enriched pathway in VZV-infected progeria cells, consistent with IPA data (Table 2). Gene ontology (GO) classification analysis also identified distinct gene lists associated with each progeria cell, highlighting the importance of genes enriched in chemokine activity (Table 3 ). Collectively, our analysis of the gene expression data revealed that functions of innate receptors for viruses, IFNs, and inflammation-mediated signals were associated with the highest rated networks in VZV-infected progeria cells.

\section{Comprehensive analysis of functional enrichment and pathways/networks of non-senescent and senescent VZV-infected NHDFs}

In order to investigate whether replicative senescence induces distinct patterns of senescenceassociated immune responses during VZV infection, we infected non-senescent and senescent NHDFs with VZV and performed transcriptome analysis using RNA-seq. The number of DEGs with a fold change of \pm 2 and a $q$-value $<0.05$ in non-senescent and senescent cells was comparable (Figure 5A). We identified 2,923 upregulated mRNAs in VZV-infected senescent cells, compared with 2,983 upregulated mRNAs in VZV-infected non-senescent cells. Venn diagrams revealed that VZV-infected senescent and non-senescent cells had 1,650 DEGs in common. In addition, chemokines, such as chemokine (C-X-C motif) ligand 8 (CXCL8), chemokine (C-C motif) ligand 7 (CCL7), and CXCL6, were among the top 10 most upregulated genes in non-senescent and senescent NHDFs infected with VZV, although expression levels of these 
Table 4: The top 10 enriched GO, molecular function terms in VZV-infected NHDF cells

\begin{tabular}{|c|c|c|}
\hline Rank & $\begin{array}{r}\text { Non-senescent NHDF } \\
(\text { GO terms, function })\end{array}$ & $\begin{array}{c}\text { Senescent NHDF } \\
\text { (GO terms, function) }\end{array}$ \\
\hline 1 & $\begin{array}{c}\text { GO:0004666 prostaglandin-endoperoxide synthase } \\
\text { activity }\end{array}$ & $\begin{array}{c}\text { GO:0004666 prostaglandin-endoperoxide synthase } \\
\text { activity }\end{array}$ \\
\hline 2 & GO:0003680 AT DNA binding & GO:0050501 hyaluronan synthase activity \\
\hline 3 & GO:0004947 bradykinin receptor activity & GO:0004947 bradykinin receptor activity \\
\hline 4 & $\begin{array}{c}\text { GO:0005172 vascular endothelial growth factor } \\
\text { receptor binding }\end{array}$ & $\begin{array}{c}\text { GO:0005172 vascular endothelial growth factor } \\
\text { receptor binding }\end{array}$ \\
\hline 5 & GO:0008009 chemokine activity & GO:0042910 xenobiotic transporter activity \\
\hline 6 & $\begin{array}{c}\text { GO:0005161 platelet-derived growth factor } \\
\text { receptor binding }\end{array}$ & GO:0008009 chemokine activity \\
\hline 7 & GO:0042379 chemokine receptor binding & GO:0042379 chemokine receptor binding \\
\hline 8 & GO:0002020 protease binding & GO:0002020 protease binding \\
\hline 9 & $\begin{array}{l}\text { GO:0005242 inward rectifier potassium channel } \\
\text { activity }\end{array}$ & GO:0005125 cytokine activity \\
\hline 10 & GO:0005125 cytokine activity & hsa04620:Toll-like receptor signaling pathway \\
\hline
\end{tabular}

chemokines were found to be approximately $2 \sim 5$-fold higher in senescent cells than in non-senescent cells (Table 1). IPA also identified the chemokine signaling pathway as a key pathway involving the majority of DEGs (CXCL11, CCL7, CXCL-10, CXCL-2, and CXCL-9) across all datasets, based on the number of network interactions (Figure 5B).

Gene set enrichment analysis using KEGG identified significantly enriched functional groups according to VZV infection. Top 10 upregulated pathways activated by VZV-infected NHDFs helped identify enrichment for pathways, including the NOD-like receptor signaling pathway, cytokine-cytokine receptor interaction, cytosolic DNA-sensing pathway, chemokine signaling pathway, and RIG-I-like receptor signaling pathway (Table 2). Similar results were obtained by top 10 enriched Gene ontology (GO) analysis (Table 4). In order to investigate the possible biological interactions of DEGs, datasets representing genes with altered expression profiles were imported into the IPA tool. Highest activated networks and upstream modulators (high z-score) were identified using IPA. Figure 5B represents separate hierarchical clustering maps showing highly activated biofunctions, upstream regulators, and canonical pathways following VZV infection in non-senescent and senescent NHDFs. Acute phase response signaling, Toll-like receptors (TLRs) signaling, IL-6 signaling, NF- $\mathrm{KB}$ signaling, and p38 MAPK signaling were among the highest activated canonical pathways after VZV infection in NHDFs, which was consistent with observations of VZV-infected progeria fibroblasts. Canonical pathway analysis demonstrated that a higher z-score was observed for the roles of pattern recognition receptors in virus sensing and interferon signaling in non-senescent NHDFs than in senescent
NHDFs.

We further generated a network map of pattern recognition signaling for non-senescent and senescent NHDFs infected with VZV (Figure 6). Similar to progeria cells, notable differences included differential modulation of TLR receptors, type 1 interferon, and pro-inflammatory cytokine response between non-senescent and senescent NHDFs. Interestingly, Type 1 interferons were upregulated to a higher extent in non-senescent cells (shown in red); however, they were found to be downregulated in senescent cells (shown in green). Collectively, the functions of innate receptors for viruses, IFNs, and inflammation-mediated signals were associated with the highest rated networks in VZV-infected NHDFs, which was consistent with findings in VZV-infected progeria fibroblasts.

\section{RNA-seq analysis reveals differential gene expression related to antiviral responses in aging cells}

In order to confirm the activation of genes associated with VZV infection in the two models of cellular senescence, we used qRT-PCR assays to analyze the expression levels of selected genes involved in the IFN pathway. HGPS and NHDF cells infected with VZV exhibited significantly higher mRNA levels of IFN- $\beta$ than mock-treated cells at 24 hpi (Figure 7A). Interestingly, IFN- $\beta$ expression was significantly lower in HG5 and senescent NHDFs than in HG3 and non-senescent NHDFs (7.23-fold induction for non-senescent cells vs. 3.56 fold induction for senescent cells at $24 \mathrm{hpi}$ ). Additionally, we assessed the production of senescence-associated secretory phenotype (SASP) factors in aging cells. In both progeria 
and NHDF cells, IL-6 production was upregulated on VZV infection in a time-dependent manner (Figure 7B). Senescent NHDFs produced higher levels of IL-6, even in mock-infected controls, compared with non-senescent cells. These findings suggest that the induction patterns of proinflammatory cytokines/chemokines differ between non-senescent and senescent cells and correlate with viral replication efficiency.

We also investigated the activation of VZVmediated signaling pathways involved in the interferon pathway and inflammation. Interestingly, the highest levels of phosphorylation of the signal transducers and activators of transcription (STAT1) family of transcription factors were found in HG5 cells compared with HG3 or HG8 cells, as shown in Figure 7C. Increased phospho-STAT1 (pSTAT1) expression was observed in non-senescent NHDFs at $48 \mathrm{hpi}$, in comparison with senescent NHDF cells. Induction levels of pSTAT1 correlated well with the expression levels of IFN- $\beta$ in response to VZV infection. Additionally, p38 MAPK phosphorylation gradually increased over time in non-senescent cells, whereas it was suppressed at 72 hpi in senescent cells, which may have directly affected the production of proinflammatory molecules such as IL-6 (Figure 7C).
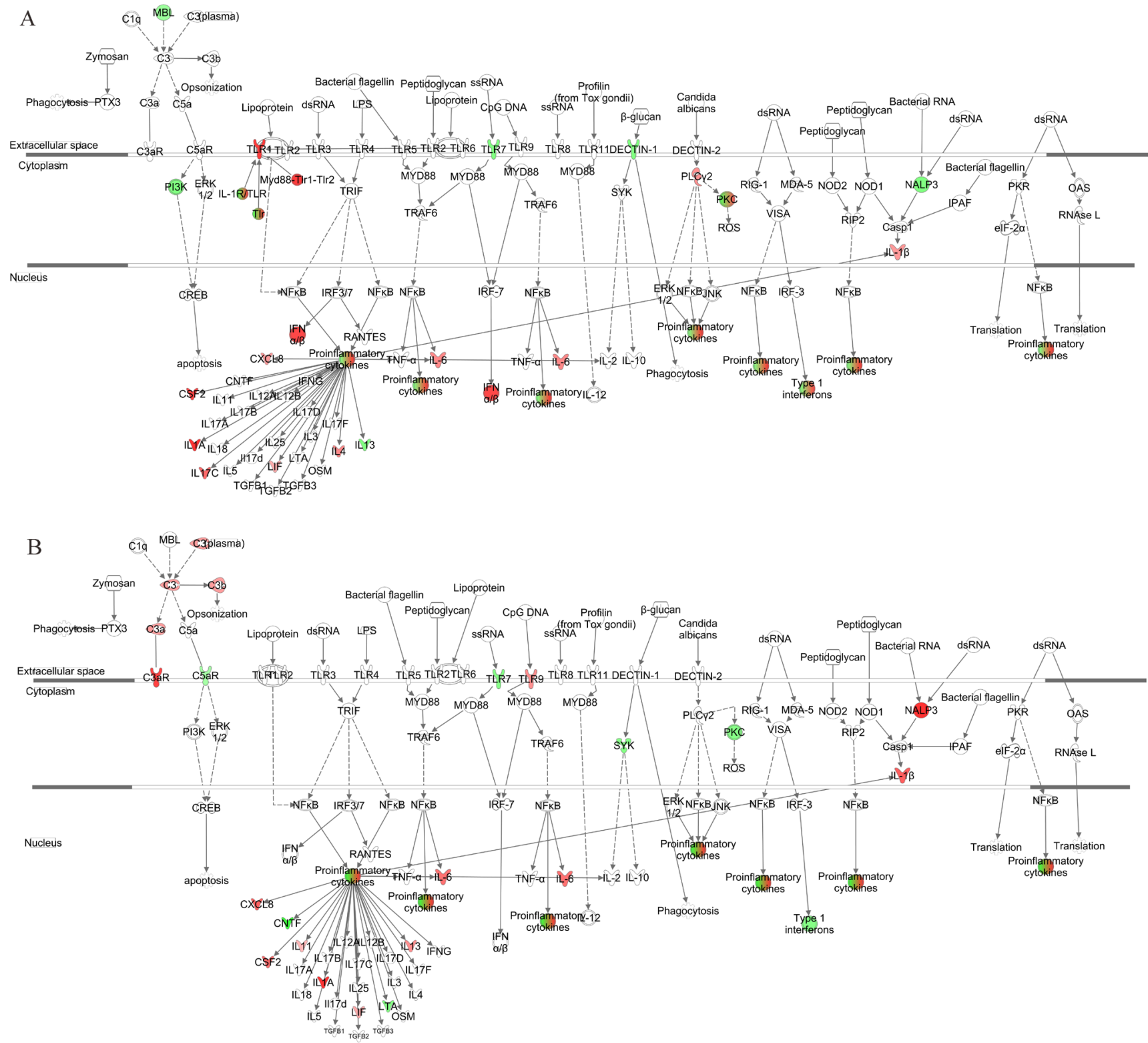

Figure 4: Pathway for pattern recognition receptor of VZV-infected HGPS cells. Genes associated with pattern recognition receptors in virus sensing network activated by VZV-infected HG3 (A) and HG5 (B) are shown. Genes associated that show differential expression are highlighted in color. Color intensity indicates the degree of upregulation (red) or downregulation (green) relative to the mock-infected HGPS cells. Solid lines represent direct interactions and dashed lines indirect interactions. 


\section{STING as a potential receptor for VZV}

VZV is a DNA virus; additionally, RNA-seq analysis identified virus sensing pattern recognition receptors as the top upregulated networks in both progeria and

A.

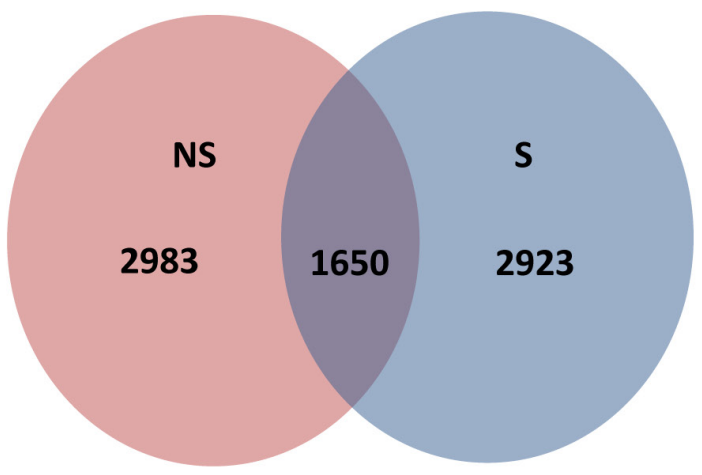

NHDF cells. Therefore, we investigated the replication efficiency of VZV after knocking down the expression of the major dsDNA-sensing NLR: stimulator of interferon genes (STING) [25]. First, we attempted to determine whether VZV infection results in the elevation of the
B

\begin{tabular}{l} 
Canonical Pathway \\
HMCB1 Signaling \\
TREM1 Signaling \\
Acute Phase Response Signaling \\
Cholecystokinin/Gastrin-mediated Signali... \\
Role of Pattern Recognition Receptors in .... \\
Interferon Signaling \\
IL-6 Signaling \\
Cardiac $\beta$-adrenergic Signaling \\
NF-kB Signaling \\
p38 MAPK Signaling \\
LXR/RXR Activation \\
PPAR Signaling \\
Ca12/13 Signaling \\
Toll-like Receptor Signaling \\
Calcium Signaling \\
Leukocyte Extravasation Signaling \\
Sperm Motility \\
CAMP-mediated signaling \\
RhoCDI Signaling \\
Cas Signaling \\
Glutamate Receptor Signaling \\
Fcy Receptor-mediated Phagocytosis in ... \\
Tec Kinase Signaling \\
Synaptic Long Term Depression \\
\hline
\end{tabular}

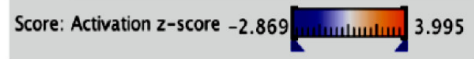

\begin{tabular}{|l|l|l|}
\hline Upstream regulators & \\
& & \\
\hline lipopolysaccharide & & \\
\hline TNF & n \\
\hline IL1B \\
poly rl:rC-RNA \\
NFkB (complex) \\
IL1A \\
IFNG \\
IFNA2 \\
SB203580 \\
MYD88 \\
IL1RN \\
LY294002 \\
PDCF BB \\
IRF7 \\
TLR3 \\
E. coli B5 lipopolysaccharide \\
IL1 \\
IL17A \\
Salmonella enterica serotype abortus eq... \\
phorbol myristate acetate \\
U0126 \\
RELA \\
IKBKB \\
\hline
\end{tabular}

Diseases and Bio Functions
cell movement
migration of cells
leukocyte migration
cell movement of myeloid cells
cell movement of mononuclear leukocytes
differentiation of cells
cell movement of leukocytes
homing of cells
homing
activation of granulocytes
cell movement of lymphocytes
chemotaxis of cells
migration of mononuclear leukocytes
proliferation of cells
chemotaxis
quantity of blood cells
inflammatory response
chemotaxis of myeloid cells
stimulation of blood cells
activation of myeloid cells
activation of phagocytes
adhesion of blood cells
cell movement of phagocytes

Figure 5: Transcriptome analysis of VZV-infected NHDFs. RNA-seq analysis was performed from RNA isolation of non-senescent (NS) and senescent (S) NHDFs that were infected with mock or VZV. (A) Venn diagrams of overlapping significantly upregulated DEG profiles for different cell types are shown. (B) The IPA tool was used to generate the list of highest activated networks and genes with their respective scores obtained from IPA and categorized as canonical pathways, upstream regulators and diseases and biofunctions. Networks and genes shaded orange were upregulated, while those in blue were downregulated. Shading intensity indicates the degree that each gene was upregulated or downregulated. Range of activation $z$-score is also depicted on the figure. 
expression levels of STING. Both mRNA and protein levels of STING were upregulated on VZV infection in primary fibroblasts (Figure 8A and $8 \mathrm{~B}$ ). Interestingly, at $24 \mathrm{hpi}$, the level of induction of STING was higher in non-senescent cells than in senescent cells. In order to determine whether knockdown or overexpression of STING in MRC-5 cells affects the efficiency of viral replication, we transfected cells with STING-specific short interfering RNAs (siRNAs) or overexpressed HAtagged STING plasmid prior to infection with VZV for $24 \mathrm{~h}$. Overexpression of STING was confirmed by determining the expression levels of STING and HA for transfection efficiency. Silencing of STING expression led to a significant increase in the expression of VZV genes ORF14 and ORF63 (Figure 8C); however, similar levels of ORF14 and ORF63 were observed in cultures with overexpressed STING. Western blotting revealed a significant attenuation of STING protein expression following siRNA treatment. Increased $\mathrm{gE}$ expression was observed following STING knockdown in primary fibroblasts (Figure 8D). Additionally, investigation of the downstream effects of STING knockdown revealed
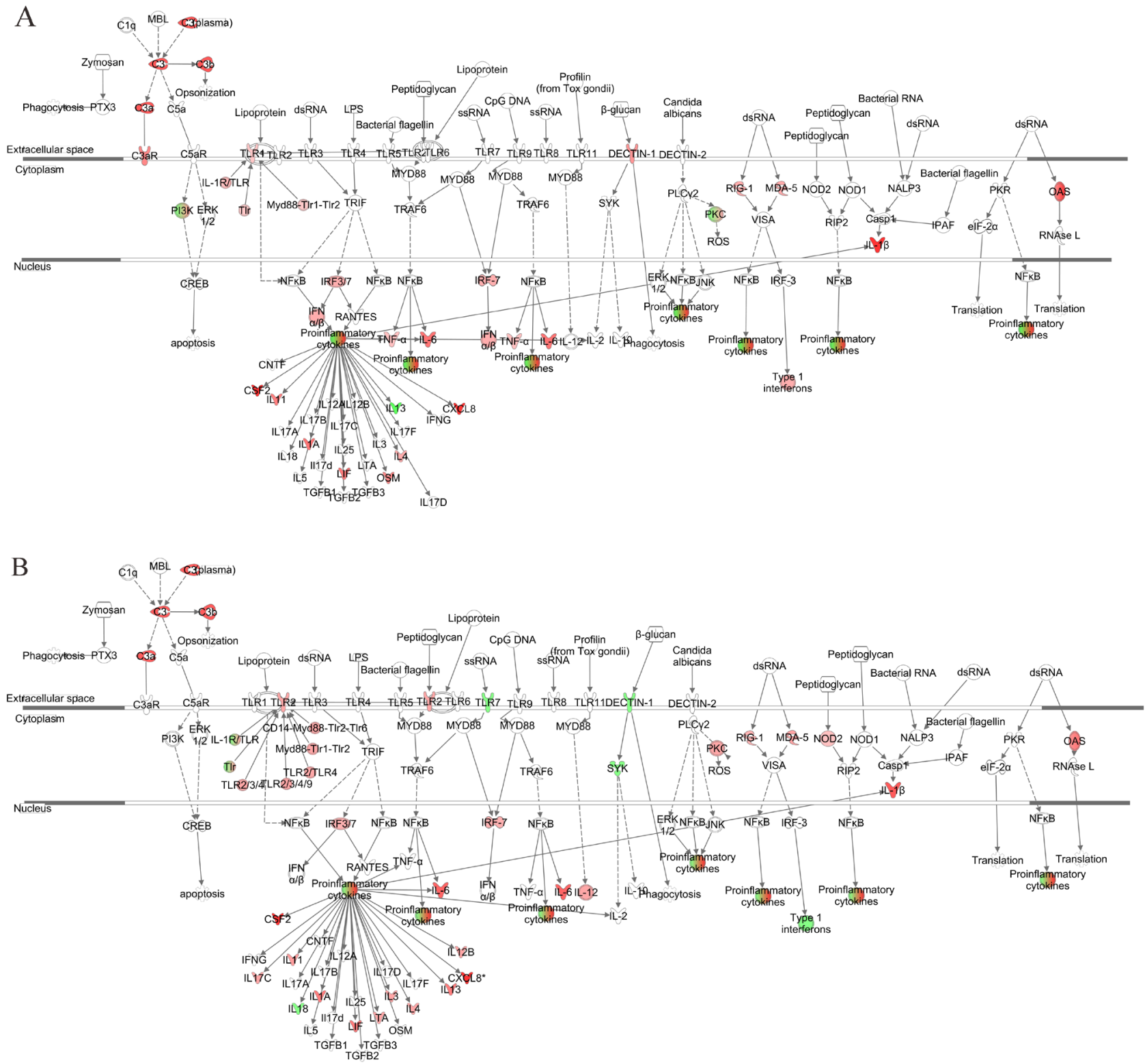

Figure 6: Network analysis for pattern recognition receptor of VZV-infected NHDFs. Genes associated with pattern recognition receptors in virus sensing network activated by VZV-infected non-senescent (A) and senescent (B) NHDFs are shown. Genes associated that show differential expression are highlighted in color. Color intensity indicates the degree of upregulation (red) or downregulation (green) relative to the mock-infected NHDFs. Solid lines represent direct interactions and dashed lines indirect interactions. 
that phosphorylation of STAT1, which signals expression of interferon-induced antiviral genes, was correlatively reduced. STING overexpression led to suppression of VZV gE synthesis. Furthermore, STING knockdown contributed to a 2-fold increase in VZV titers $(p<0.05)$ at $48 \mathrm{~h}$ post-transfection in primary fibroblasts, whereas STING overexpression resulted in a significant increase in VZV plaque numbers (Figure 8E). Our results indicate that the STING-mediated STAT1 antiviral pathway may be essential in controlling viral replication.

\section{DISCUSSION}

The reactivation of VZV causes shingles, which is associated with significant morbidity, and sometimes, mortality in the elderly. Shingles potentially has a devastating impact on the patient's quality of life [26]. However, the role of immunosenescence during VZV infection is poorly understood. Moreover, currently available vaccines against VZV show poor efficacy in the elderly. In order to characterize the aspects of
A.

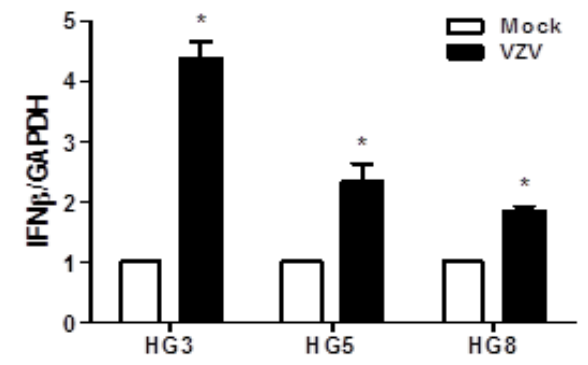

B.

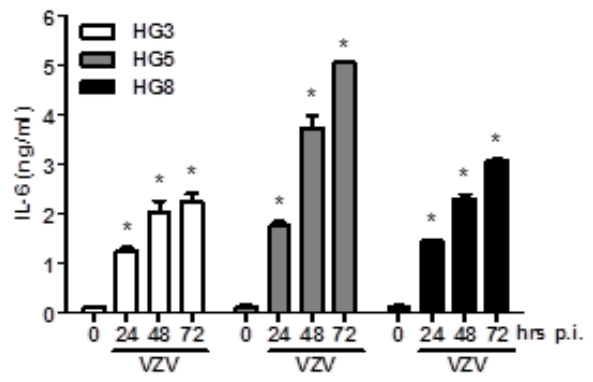

c.

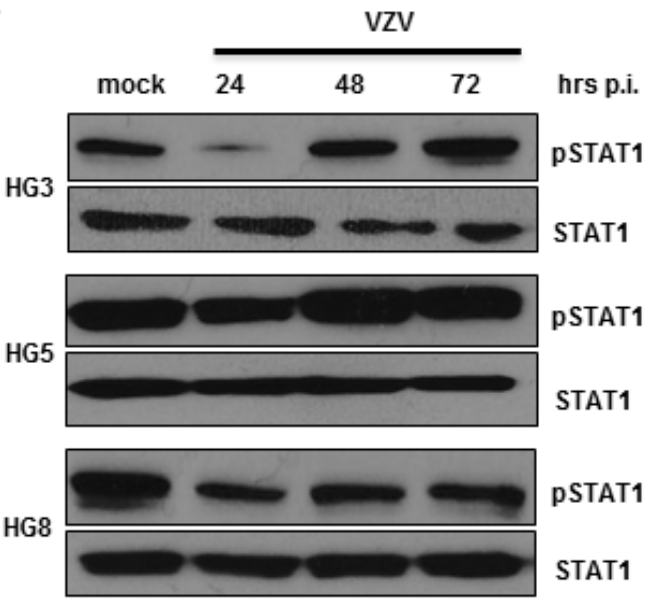

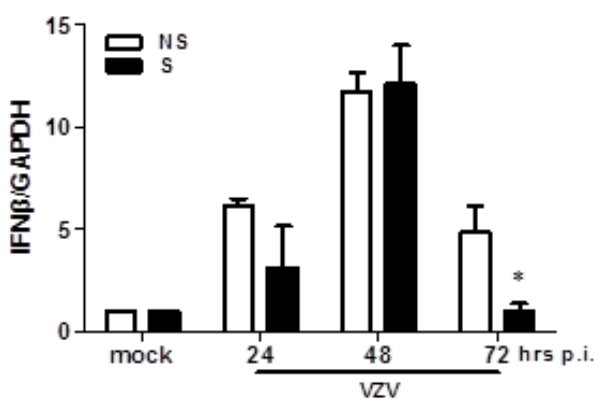
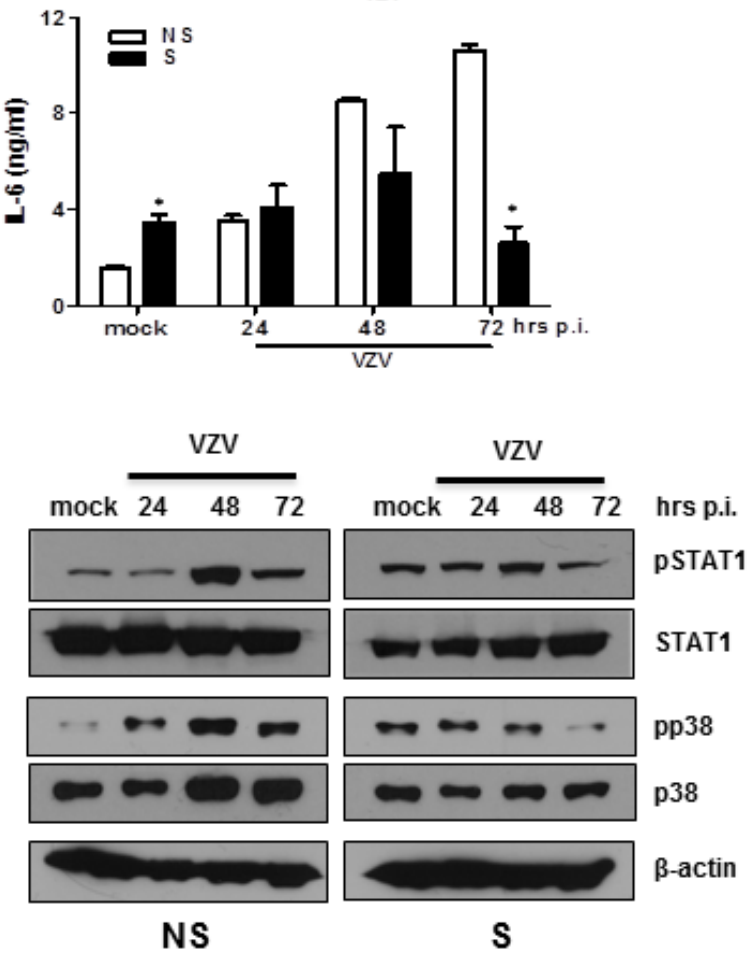

Figure 7: Validation of DEGs in VZV-infected non-senescent and senescent cells that are involved in antiviral responses and inflammation. HGPS cells and NHDFs were infected with VZV at an MOI of 0.001 for indicated timepoints $(0,24,48$, and 72 hpi). (A) RNA was extracted and cDNA was made to perform qPCR. Host IFN- $\beta$ mRNA expression levels were determined by qPCR. Expression levels were normalized to GAPDH. Mock-infected cells were arbitrarily set to 1 . We performed qPCR assays in duplicate, with the mean \pm SD from all experiments shown. ${ }^{*} p<0.05$ vs. mock-infected cells (HGPS) and NS cells (NHDFs). (B) The concentration of secreted IL-6 in culture supernatants from HGPS cells and NHDFs was determined using enzyme-linked immunosorbent assays (ELISAs). Values presented are the averages from all experiments, with error bars representing SDs. ${ }^{*} p<0.05$ vs. mock-infected cells (HGPS) and NS cells (NHDFs). (C) Cells were lysed and cell extracts were separated by SDS-PAGE and blotted onto nitrocellulose membranes. Protein levels of phosphorylated/total STAT1, and phosphorylated/total p38 MAPK were analyzed by western blotting. Anti- $\beta$-actin monoclonal antibody was used as a loading control. The images shown are representative of three independent experiments. 
A.

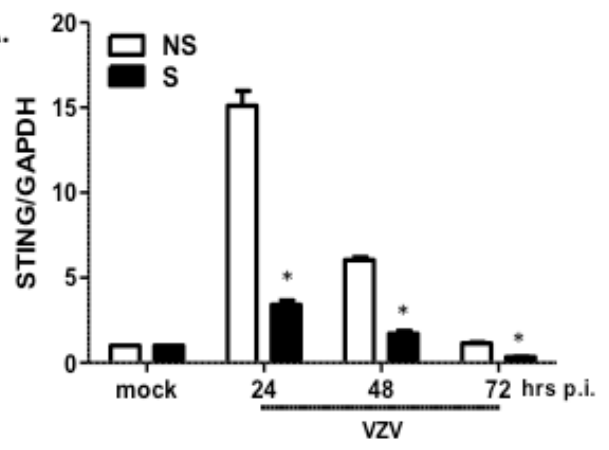

C.

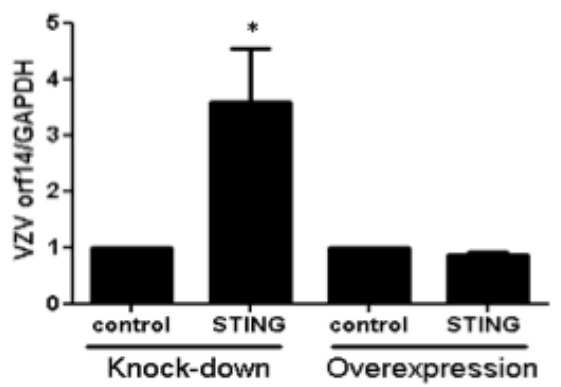

D.

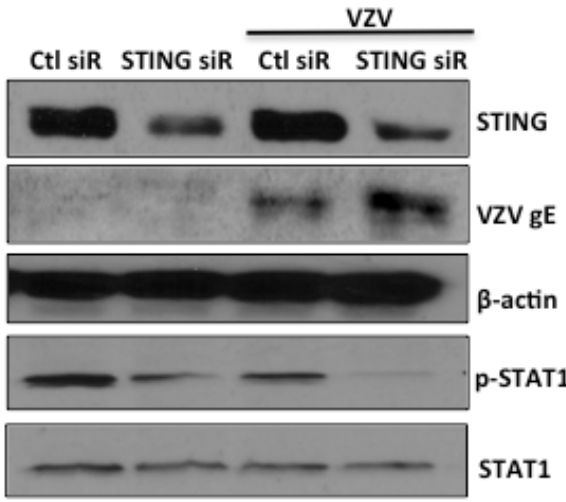

B.

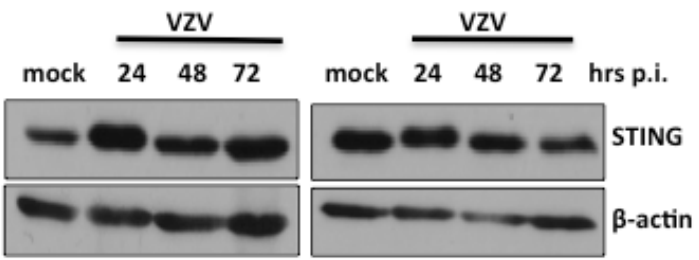

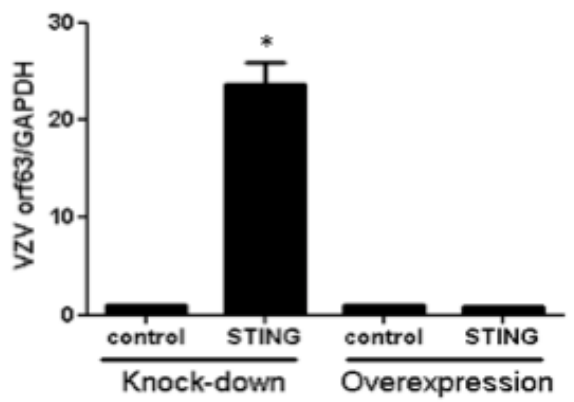

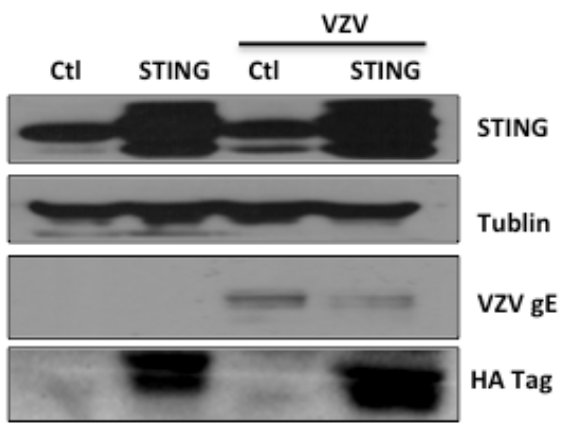

E.
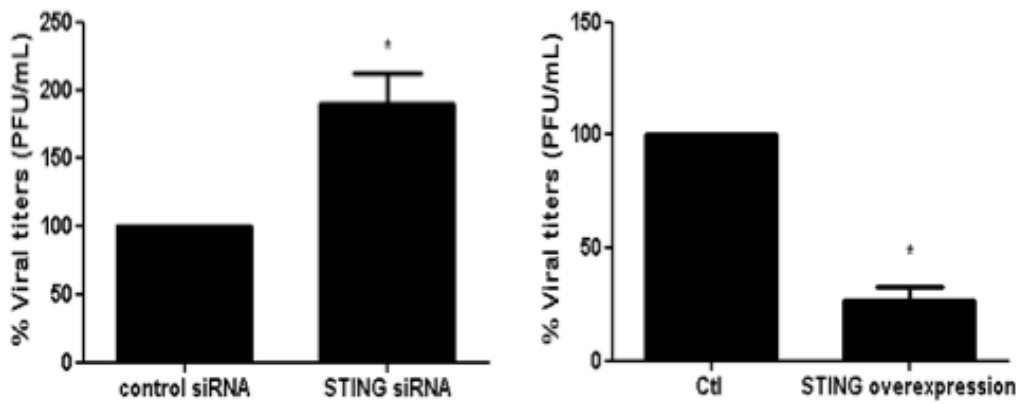

Figure 8: STING plays an important role in modulating replication of VZV. (A) NS and S NHDFs were infected with VZV at an MOI of 0.001 for indicated time points. Host STING mRNA expression levels were measured by qPCR. The expression of STING was normalized to GAPDH. NS cells that were mock infected were arbitrarily set to 1 . We performed qPCR assays in duplicate. The mean $\pm \mathrm{SD}$ from three independent experiments is shown. ${ }^{*} p<0.05$ vs. NS cells. (B) Western blotting detection of STING is shown. The blot shown is representative of results from three independent experiments. (C) MRC-5 cells were transfected with STING-specific siRNAs or STINGHA expression plasmids and infected with VZV at MOI 0.01. VZV ORF14 (late) and 63 (immediate early) gene expressions were measured by qPCR. Transcript expression levels were calculated in relation to the expression level of GAPDH mRNAs. We performed qPCR assays in duplicate, with the mean $\pm \mathrm{SD}$ from all experiments shown. ${ }^{*} p<0.05$ compared with control siRNA-transfected cells or control plasmidtransfected cells. (D) STING, pSTAT1, total STAT1, VZV gE were detected by western blotting (left: STING knockdown, right: STING overexpression). $\beta$-actin and tubulin were used as a loading control. Images shown are representative of results from three independent experiments. (E) Progeny VZV titers $(\mathrm{PFU} / \mathrm{mL})$ were calculated and presented as the mean $\pm \mathrm{SD}$ from three different experiments, and as a percentage of control siRNAs. ${ }^{*} p<0.05$ compared with control siRNA-transfected cells or control plasmid-transfected cells. 
immunosenescence that contribute to increased VZV susceptibility, a clinical strain of VZV was isolated from a patient with shingles and used to infect two aging cell models: HGPS fibroblasts and replicative senescence-induced NHDFs. Using high throughput RNA-seq technology to comprehensively annotate host transcriptomes following infection, the present work illustrates the effects of immunosenescence in aging cells on viral replication efficiency and host signaling pathways.

VZV replication in skin cells is crucial for viral pathogenesis. Accordingly, we compared the transcription levels of major VZV genes, such as ORF14 and ORF 63 , in aging skin cell models. Transcript levels of VZV immediate early gene (ORF63) in senescent cells (both stress-induced and replicative senescence) were found to be significantly higher than in non-senescent cells at 24 hpi. On the other hand, a relatively moderate induction of interferon signaling genes, such as IFN- $\beta$, was detected in senescent cells compared with non-senescent cells. This observation may reflect a close correlation between viral replication efficiency and host responses related to virus sensing and antiviral defense mechanisms. Given that the production of type I IFNs and the subsequent induction of IFN-stimulated genes (ISGs) is inhibited by various ORFs of VZV, such as ORF61, ORF62, and ORF47 [27-29], a detailed profile of dual viral and host gene expression patterns at various stages post-infection would provide a valuable insight into temporal changes in host/pathogen interaction.

The question of whether HGPS actually recapitulates the normal aging process at the cellular and organism levels has received much attention. Recent studies indicate that signaling pathway activation states in cells derived from chronologically young patients with HGPS strongly resemble those in cells from normal middle-aged and elderly individuals [10]. Mutations in the $L M N A$ gene of patients with HGPS results in increased rates of cellular apoptosis, and consequently, a premature loss of functional "young" cells and concomitant premature accumulation of senescent cells $[30,31]$. When we compared cellular morphology and proliferation patterns in fibroblasts derived from different age groups of patients with HGPS, we noticed that HG8 fibroblasts (isolated from an 8-year-old patient with HGPS) displayed a distinct cellular morphology, evidenced by maximal senescenceassociated $\beta$-gal staining. In accordance with this data, VZV infection was found to induce an approximately 2-fold higher number of DEGs in HG8 fibroblasts than in HG3 and HG5 fibroblasts, as shown by Venn diagram and IPA analysis, although many of the DEGs identified were found to be unrelated to immune function (Figure 3 ). The unique cellular phenotype of HG8 fibroblasts potentially explains the low level of VZV replication, followed by the weak response to type I IFN, in these cells compared with HG3 and HG5 fibroblasts (Figure 1 and 7).

IPA analysis revealed that during the early stages of VZV infection, the triggering receptor expressed on myeloid cells 1 (TREM1) signaling pathway, PRRs of bacteria and viruses, IFN response, and p38 MAPK signaling are upregulated in both progeria cells and NHDFs infected with VZV. The TREM1 pathway, an essential regulator of antiviral immunity [32], was found to be the top predicted canonical pathway to be activated following B cell receptor-mediated reactivation of EpsteinBarr virus [33]. TREM1 is upregulated to a higher extent in HG5 cells than in HG3 or HG8 cells, whereas nonsenescent NHDFs exhibit increased TREM1 expression than senescent NHDFs. Accordingly, in the present study, IPA analysis of VZV-infected senescent cells revealed that genes involved in virus-mediated inflammatory processes, such as TREM1 signaling, acute phase response signaling, and virus receptor signaling, were upregulated (Figures 3 and 5).

Age-dependent alterations in innate immune responses and interferon signaling have been noted in several studies [34]. In particular, delayed interferon production has been found to be associated with heightened susceptibility to viral infections such as those caused by the West Nile Virus (WNS) [35]. These data correlate well with the data presented in this study, in which lower production of interferon- $\beta$ was observed in aging cells, in correlation with the abrogation of phosphorylation of STAT1 at later time points during infection ( $72 \mathrm{hpi}$ ). It has recently been shown that senescence is associated with the alteration of the expression patterns of a number of genes encoding secreted proteins such as cytokines and chemokines [36]. The production of these factors, collectively referred to as SASP factors, is an essential characteristic of senescent cells. Our findings indicate that the levels of SASP factors, such as IL-6, were robustly upregulated even in the mock-infected senescent NHDFs compared with non-senescent NHDFs. However, IL-6 levels did not change significantly over time in senescent NHDFs, but continued to increase in non-senescent NHDFs. Furthermore, the phosphorylation of p38 MAPK, which occurs as part of a major signaling pathway involved in the induction of senescence [37] and also upstream of the secretion of proinflammatory cytokines such as IL6 , was induced upon VZV infection. Consistent with the reduction in IL-6 protein levels in senescent NHDFs, phosphorylation of p38 MAPK was also attenuated in these cells in comparison with non-senescent NHDFs. Interestingly, levels of efficiency of viral replication were negatively correlated with levels of activation of host signaling pathways involved in interferon regulatory genes and SASP secretion, highlighting the possibility that age-related impairment of the innate immune response contributes to increased susceptibility to VZV infection and poor response to vaccination.

Another important finding of the current study was the identification of a novel VZV recognition receptor. 
To date, little information has been published regarding the potential receptors of VZV [1, 38]. Given that VZV possesses a DNA genome, it is highly likely that the intracellular sensing system of the host is important for VZV recognition. Recent studies indicate that STING is essential for activation of TANK-binding kinase 1 (TBK1) signaling pathways in response to herpes simplex virus-1 (HSV-1) infection. [39, 40]. In the present study, we demonstrate that siRNA-mediated silencing of STING and the subsequent abrogation of downstream molecule STAT1 in human fibroblasts leads to elevated viral titers (Figure 6). These findings suggest that STING also plays an important role in enhancing immunity against VZV infection. It is highly plausible that STING knockdown may have resulted in decreased antiviral signaling and subsequent reduction in interferon gene expression, potentially contributing to the induction of higher viral titers in VZV-infected cells. STING knockdown in Japanese encephalitis virus (JEV) infection model has also been found to result in increased intracellular viral load, whereas overexpression contributed to decreased viral titers [41]. Although STING is essential for IFN responses against herpes simplex virus [40], its role during VZV infection has not been previously demonstrated. STINGmediated IFN responses have been shown to be inhibited by age-enhanced endoplasmic reticulum stress during Streptococcus pneumoniae infection in an in vivo model [42]. We also compared the mRNA and protein expression levels of STING in non-senescent and senescent NHDFs, and found that senescence led to decreased STING mRNA expression at all time points (24, 48, and $72 \mathrm{hpi})$. As VZV is capable of evading innate immune activation, further investigation of the viral proteins that interact with STING would be of interest. Given that STING agonists have been considered potential adjuvant candidates, our study of STING as a potential receptor for VZV raises the possibility that a STING agonist may be useful as an adjuvant for vaccines against shingles.

Collectively, our data provide a comprehensive transcriptome analysis of aged human fibroblasts infected with VZV. Genes involved in several biological pathways related to innate antiviral immunity and inflammation were among the top DEGs. Differential expression of specific factors observed in aging cells may explain the observed variation in innate immune responses. These findings provide a framework for future studies examining the molecular mechanisms underlying the pathogenicity of VZV. Further global studies involving patients of different age groups with shingles should provide valuable insights into the efficient replication of VZV and suppression of the antiviral response in the elderly.

\section{MATERIALS AND METHODS}

\section{Cells}

Primary skin fibroblasts were obtained from the Progeria Research Foundation Cell and Tissue Bank (http://www.progeriaresearch.org/cell tissue bank.html). The HGPS cell lines HGADFN127, HGADFN122, and HGADFN167 were derived from 3-, 5-, and 8-year-old donors, respectively. Cells were maintained in Dulbecco's modified Eagle's medium (DMEM; Invitrogen, Carlsbad, CA, USA) supplemented with $15 \%$ fetal bovine serum (FBS), $2 \mathrm{mM}$ L-glutamine, 50 units/mL penicillin, $50 \mu \mathrm{g} /$ $\mathrm{mL}$ streptomycin, and $10 \mathrm{mM}$ non-essential amino acids (Invitrogen) at $37^{\circ} \mathrm{C} / 5 \% \mathrm{CO}_{2}$. Normal fibroblasts typically grew for around 30 passages; however, HGPS fibroblasts were used before 10 passages, under the same culturing conditions.

NHDFs were purchased from Lonza, Basel, Switzerland. For stress-induced senescence, hydrogen peroxide (Sigma, St. Louis, MO, USA) was added at a concentration of $100 \mathrm{nM}$ to cells in 6-well plates and incubated for $1 \mathrm{~h}$ before the addition of virus. For replication-induced senescence, NHDFs (Lonza, Basel, Switzerland) were grown as adherent cultures in fibroblast basal medium supplemented with FGM SingleQuots (Lonza). Non-senescent cells were defined as lowpassage-number cells (less than 7 passages), whereas senescent cells were considered high-passage-number cells (more than 20 passages with positive $\beta$-galactosidase staining). MRC-5 cells (human lung fibroblasts) were obtained from ATCC (Manassas, VA, USA) and grown in DMEM (Lonza) with 10\% HyClone FBS (GE Healthcare) and antibiotics.

\section{Senescence model}

Stress-mediated senescence was induced by hydrogen peroxide $\left(\mathrm{H}_{2} \mathrm{O}_{2}\right)$ treatment of non-senescent NHDFs. Senescence was validated as the percentage of senescence-associated $\beta$-galactosidase (SA- $\beta$-Gal) stained cells. For replicative senescence, NHDFs were allowed to grow for more than 20 passages, and senescent cells were verified by their delayed population-doubling times and through the use of a Senescence $\beta$-Galactosidase Staining Kit (Cell Signaling Technology, MA, USA), as described previously [22]. After staining, cells were washed and assessed by light microscopy (Olympus, Tokyo, Japan). For 4,6-diamidino-2-phenylindole (DAPI) staining, cells were grown in 24-well plates. After $24 \mathrm{~h}$ of incubation at $37^{\circ} \mathrm{C}$ and $5 \% \mathrm{CO}_{2}$, cells were fixed with ice-cold $4 \%$ paraformaldehyde for $10 \mathrm{~min}$ and washed twice with PBS. Cells were then permeabilized with $100 \%$ methanol for $10 \mathrm{~min}$, and coverslips with adherent cells were mounted 
onto glass slides using mounting media containing DAPI (Sigma) for visualization by confocal microscopy (Zeiss LSM700).

\section{VZV plaque assays}

The previously described VZV strain YC01 (GenBank Accession No. KJ808816) (Won, Kim, Kim, \& Lee, 2014) was cultured in human fetal fibroblasts (HFFs). Progeria fibroblasts or NHDF cells were infected with VZV at a MOI of 0.001 or 0.01 . VZV-infected cells were diluted 10-fold and used to inoculate confluent uninfected HFF monolayers. After adsorption for $1 \mathrm{~h}$, viruscontaining media were removed and fresh media added to cultures. Cells were washed with media and incubated at $37^{\circ} \mathrm{C}$ and $5 \% \mathrm{CO}_{2}$. After $3 \sim 7$ days, cells were fixed with $4 \%$ formaldehyde and stained with $0.03 \%$ crystal violet. Plaques were counted using a phase-contrast microscope.

\section{Gene expression analysis using RNA-seq}

Total RNA from primary fibroblast cultures was isolated using TRIzol reagent (Invitrogen Life Technologies). The quality of all RNA samples was assessed using a Bioanalyzer 2100 (Agilent Technologies, Santa Clara, CA, USA). Generation of the RNAseq library for each sample was carried out using the manufacturer's recommended protocols for an Illumina HiSeq2500 (Illumina, San Diego, CA, USA), to generate $101 \mathrm{bp}$ paired-end reads. Reads that passed quality control were mapped to human IGenome (Ensembl_CRCh37) using Tophat2 (v2.0.13), and were counted using HTseq (v0.6.1p1).

\section{Identification of DEGs and functional analysis (GO, KEGG)}

EdgeR (v3.4.2) was used to identify DEGs; this program used the Cox-Reid profile-adjusted likelihood method to estimate dispersion for pairwise comparisons. After negative binomial models are fitted and dispersion estimates are obtained, a generalized linear model (GLM) likelihood ratio test was used to determine differential expression. In this study, genes with $\geq 2$-fold change and FDR-adjusted $q$ value $<0.05$ were considered significantly differentially expressed. Functional classification of genes was performed using the Database for Annotation, Visualization, and Integrated Discovery (DAVID) (http:// david.abcc.ncifcrf.gov/). The representation of functional groups in each sample relative to the whole genome was investigated using the Expression Analysis Systematic Explorer (EASE) tool [25] within DAVID. The EASE tool uses a modified Fisher's exact test to measure enrichment of gene ontology (GO) terms. In order to identify enriched
GO terms, functionally clustered genes were filtered using an EASE value less than 0.05 and selected. KEGG pathway analysis was also used for target gene candidates. Genes with FDR $<0.05$ were considered as significantly enriched among target gene candidates.

\section{Ingenuity pathway analysis (IPA)}

Data were analyzed using QIAGEN's Ingenuity Pathway Analysis (IPA) (QIAGEN Redwood City, USA). The most significant canonical pathways and functional processes of biological importance were selected using the list of DEGs identified by RNA-seq and the Ingenuity Pathways Knowledge Base. The Ingenuity Knowledge Base contains the largest database of manually curated and experimentally validated physical, transcriptional, and enzymatic molecular interactions. Furthermore, each interaction in the Ingenuity Knowledge Base is supported by previously published information. The list of DEGs was overlaid onto a global molecular network developed from information contained in the Ingenuity Pathways Knowledge Base, and networks were algorithmically generated on the basis of connectivity. Pathway enrichment p-values (Fisher's exact test) and activation $z$-scores were calculated by IPA.

\section{qPCR assays}

Total RNA was isolated using TRIzol reagent (Life Technologies). First-strand synthesis of cDNA from total RNA was performed using ImProm-II ${ }^{\mathrm{TM}}$ Reverse Transcription System (Promega, Madison, WI, USA) according to the manufacturer's instructions. Quantitation of cDNA was performed by qPCR with SYBR Green PCR Master Mix (Life Technologies). Thermal cycling parameters consisted of an initial denaturation step at $95^{\circ} \mathrm{C}$ for $10 \mathrm{~min}$, followed by 40 amplification cycles $\left(95^{\circ} \mathrm{C}\right.$ for $30 \mathrm{~s}, 60^{\circ} \mathrm{C}$ for $\left.1 \mathrm{~min}\right)$. Primer sequences are available on request. The specificity of each reaction was confirmed by melting curve analysis and agarose gel electrophoresis of PCR products. The expression of target genes was normalized to that of human glyceraldehyde 3-phosphate dehydrogenase (GAPDH) and analyzed using the comparative $\mathrm{Ct}$ method.

\section{Enzyme-linked immunosorbent assays (ELISAs)}

In order to determine the concentration of interleukin (IL)-6 in samples, we used a specific ELISA kit (BioLegend, San Diego, CA, USA) according to the manufacturer's instructions. Absorbance at $450 \mathrm{~nm}$ was determined using a microplate spectrophotometer. Protein concentrations were calculated based on standard curves generated using known concentrations of IL-6. 


\section{Western blotting analysis}

Cells were lysed at the specified times post-infection with lysis buffer $(0.05 \mathrm{M}$ Tris, $\mathrm{pH} 7.4,0.15 \mathrm{M} \mathrm{NaCl}, 0.5$ $\mathrm{mM}$ phenylmethylsulfonyl fluoride, $50 \mu \mathrm{g} / \mathrm{mL}$ aprotinin, $10 \mu \mathrm{g} / \mathrm{mL}$ leupeptin, $50 \mu \mathrm{g} / \mathrm{mL}$ pepstatin, $0.4 \mathrm{mM}$ sodium orthovanadate, $10 \mathrm{mM} \mathrm{NaF}$, and $10 \mathrm{mM}$ sodium pyrophosphate). Lysates were resolved by sodium dodecyl sulfate polyacrylamide gel electrophoresis (SDS-PAGE) on $10-12 \%$ acrylamide gels. Proteins were transferred to polyvinylidene difluoride (PVDF) membranes, and blocked with $5 \%(\mathrm{w} / \mathrm{v})$ skim milk in Tris-buffered saline $(0.2 \mathrm{M}$ Tris, $1.36 \mathrm{M} \mathrm{NaCl})$ supplemented with $0.1 \%$ (v/v) Tween-20 (TBS-T) for $1 \mathrm{~h}$ at room temperature. Membranes were washed with $15 \mathrm{~mL}$ of TBS-T and then incubated with primary antibody for $1 \mathrm{~h}$ at $25^{\circ} \mathrm{C}$. After further washing with TBS-T, membranes were incubated with the appropriate horseradish peroxidase (HRP)-conjugated antibody for $1 \mathrm{~h}$ at $25^{\circ} \mathrm{C}$. Membranes were washed with TBS-T and incubated with Pierce ECL Western blotting substrate kit (Thermo Scientific), and exposed to film. We used a mouse anti-VZV gE antibody (ab52549; Abcam) diluted 1:10,000 to detect major VZV glycoproteins, followed by an anti-mouse HRPconjugated antibody (1:5,000; Invitrogen). Antibodies against HA, phospho-STAT1, STAT1, and STING were purchased from Cell Signaling Technology, and anti- $\beta$ actin (Abgent), anti-tubulin (Abgent), and anti-GAPDH (Sigma) antibodies were used as internal controls.

\section{Overexpression and knockdown experiments}

MRC-5 cells were seeded in 6-well plates and allowed to grow until cultures were $70 \%$ confluent on the day of transfection. Transient transfections with either scrambled control or STING-specific siRNAs (Bioneer, Daejeon, Korea) were performed using Lipofectamine ${ }^{\circledR}$ (Invitrogen), according to the manufacturer's protocol. Briefly, $1 \mu \mathrm{L}$ of STING siRNA and $5 \mu \mathrm{L}$ of Lipofectamine ${ }^{\circledR}$ were mixed with $100 \mu \mathrm{L}$ of Opti-MEM ${ }^{\circledR}$ (Invitrogen). The mixture was incubated for $15 \mathrm{~min}$ at room temperature and then added dropwise to each culture well containing 1 $\mathrm{mL}$ of Opti-MEM ${ }^{\circledR}$. At $6 \mathrm{~h}$ post-transfection, transfection medium was aspirated and fresh growth medium was added. At $24 \mathrm{~h}$ post-transfection, cells were infected with VZV strain YC01 at an MOI of 0.01. Cells were cultured for $24 \mathrm{~h}$, lysed, and lysates subjected to western blotting to determine STING expression levels. For overexpression of STING $4 \mu \mathrm{g}$ of STING-pUNO-HA plasmid (Invivogen) was transfected using InFECT transfection reagent (iNtRON Biotechnology, Korea) according to the manufacturer's instructions.

\section{Statistical analysis}

Results were expressed as the means \pm standard deviation (SD). Data were analyzed using Student's t-test to determine statistically significant differences between two groups. Statistical analyses were performed using GraphPad Prism (GraphPad Software, La Jolla, CA, USA). A $p$-value of $<0.05$ was considered statistically significant.

\section{ACKNOWLEDGMENTS}

We would like to thank the Progeria Foundation for providing HGPS cells. This study was supported by grants from the Korea Healthcare Technology Research and Development Project of the Ministry of Health and Welfare (Grant No. R1417262) and grant number P30GM114737, from the Centers of Biomedical Research Excellence program of the National Institute of General Medical Sciences, National Institutes of Health.

\section{CONFLICTS OF INTEREST}

The authors declare that there are no conflicts of interest that may be perceived as prejudicing the impartiality of the research reported.

\section{Authors' contributions}

Conceived and designed the experiments: SKP, JAK, OSS.

Performed the experiments: SKP, JAK, MK.

Analyzed the data: SKP, JAK, MK, OSS.

Contributed reagents/materials/analysis tools: SKP, JAK, MK, CHL, OSS.

Wrote the paper: MK, OSS.

\section{REFERENCES}

1. Zerboni L, Sen N, Oliver SL and Arvin AM. Molecular mechanisms of varicella zoster virus pathogenesis. Nature reviews Microbiology. 2014; 12:197-210.

2. Diaz PS, Smith S, Hunter E and Arvin AM. T lymphocyte cytotoxicity with natural varicella-zoster virus infection and after immunization with live attenuated varicella vaccine. Journal of immunology. 1989; 142:636-641.

3. Shapiro M, Kvern B, Watson P, Guenther L, McElhaney $\mathrm{J}$ and McGeer A. Update on herpes zoster vaccination: a family practitioner's guide. Canadian family physician Medecin de famille canadien. 2011; 57:1127-1131.

4. Raeder CK and Hayney MS. Immunology of Varicella Immunization in the elderly. The Annals of pharmacotherapy. 2000; 34:228-234.

5. van Deursen JM. The role of senescent cells in ageing. 
Nature. 2014; 509:439-446.

6. Solana R, Tarazona R, Gayoso I, Lesur O, Dupuis G and Fulop T. Innate immunosenescence: effect of aging on cells and receptors of the innate immune system in humans. Seminars in immunology. 2012; 24:331-341.

7. Marin M, Yawn BP, Hales CM, Wollan PC, Bialek SR, Zhang J, Kurland MJ and Harpaz R. Herpes Zoster Vaccine Effectiveness and Manifestations of Herpes Zoster and Associated Pain by Vaccination Status. Human vaccines \& immunotherapeutics. 2015:0.

8. DeBusk FL. The Hutchinson-Gilford progeria syndrome. Report of 4 cases and review of the literature. The Journal of pediatrics. 1972; 80:697-724.

9. Gordon LB, Brown WT and Collins FS. (1993). Hutchinson-Gilford Progeria Syndrome. In: Pagon RA, Adam MP, Ardinger HH, Bird TD, Dolan CR, Fong CT, Smith RJH and Stephens K, eds. GeneReviews(R). (Seattle (WA).

10. Aliper AM, Csoka AB, Buzdin A, Jetka T, Roumiantsev S, Moskalev A and Zhavoronkov A. Signaling pathway activation drift during aging: Hutchinson-Gilford Progeria Syndrome fibroblasts are comparable to normal middle-age and old-age cells. Aging. 2015; 7:26-37.

11. Goldman RD, Shumaker DK, Erdos MR, Eriksson M, Goldman AE, Gordon LB, Gruenbaum Y, Khuon S, Mendez M, Varga R and Collins FS. Accumulation of mutant lamin A causes progressive changes in nuclear architecture in Hutchinson-Gilford progeria syndrome. Proceedings of the National Academy of Sciences of the United States of America. 2004; 101:8963-8968.

12. Viteri G, Chung YW and Stadtman ER. Effect of progerin on the accumulation of oxidized proteins in fibroblasts from Hutchinson Gilford progeria patients. Mechanisms of ageing and development. 2010; 131:2-8.

13. Paradisi M, McClintock D, Boguslavsky RL, Pedicelli C, Worman HJ and Djabali K. Dermal fibroblasts in Hutchinson-Gilford progeria syndrome with the lamin A G608G mutation have dysmorphic nuclei and are hypersensitive to heat stress. BMC cell biology. 2005; 6:27.

14. Gavazzi G and Krause KH. Ageing and infection. The Lancet Infectious diseases. 2002; 2:659-666.

15. Mei B, Ding X, Xu HZ and Wang MT. Global gene expression changes in human peripheral blood after H7N9 infection. Gene. 2014; 551:255-260.

16. Wang Y, Lupiani B, Reddy SM, Lamont SJ and Zhou H. RNA-seq analysis revealed novel genes and signaling pathway associated with disease resistance to avian influenza virus infection in chickens. Poultry science. 2014; 93:485-493.

17. Ertl R and Klein D. Transcriptional profiling of the host cell response to feline immunodeficiency virus infection. Virology journal. 2014; 11:52.

18. Jones M, Dry IR, Frampton D, Singh M, Kanda RK, Yee MB, Kellam P, Hollinshead M, Kinchington PR, O'Toole
EA and Breuer J. RNA-seq analysis of host and viral gene expression highlights interaction between varicella zoster virus and keratinocyte differentiation. PLoS pathogens. 2014; 10:e1003896.

19. Rossetto CC, Tarrant-Elorza M, Verma S, Purushothaman $\mathrm{P}$ and Pari GS. Regulation of viral and cellular gene expression by Kaposi's sarcoma-associated herpesvirus polyadenylated nuclear RNA. Journal of virology. 2013; 87:5540-5553.

20. Juranic Lisnic V, Babic Cac M, Lisnic B, Trsan T, Mefferd A, Das Mukhopadhyay C, Cook CH, Jonjic S and Trgovcich J. Dual analysis of the murine cytomegalovirus and host cell transcriptomes reveal new aspects of the virus-host cell interface. PLoS pathogens. 2013; 9:e1003611.

21. Korf B. Hutchinson-Gilford progeria syndrome, aging, and the nuclear lamina. The New England journal of medicine. 2008; 358:552-555.

22. Lee BY, Han JA, Im JS, Morrone A, Johung K, Goodwin EC, Kleijer WJ, DiMaio D and Hwang ES. Senescenceassociated beta-galactosidase is lysosomal betagalactosidase. Aging cell. 2006; 5:187-195.

23. Won YH, Kim JI, Kim YY and Lee CH. Characterization of the Repeat Sequences of Varicella-Zoster Virus. Journal of Bacteriology and Virology. 2014; 44:326-335.

24. Cristofalo VJ and Pignolo RJ. Replicative senescence of human fibroblast-like cells in culture. Physiological reviews. 1993; 73:617-638.

25. Konno H and Barber GN. The STING controlled cytosolicDNA activated innate immune pathway and microbial disease. Microbes and infection / Institut Pasteur. 2014; 16:998-1001.

26. McElhaney JE. Herpes zoster: a common disease that can have a devastating impact on patients' quality of life. Expert review of vaccines. 2010; 9:27-30.

27. Zhu H, Zheng C, Xing J, Wang S, Li S, Lin R and Mossman KL. Varicella-zoster virus immediate-early protein ORF61 abrogates the IRF3-mediated innate immune response through degradation of activated IRF3. Journal of virology. 2011; 85:11079-11089.

28. Vandevenne P, Lebrun M, El Mjiyad N, Ote I, Di Valentin E, Habraken Y, Dortu E, Piette J and Sadzot-Delvaux C. The varicella-zoster virus ORF47 kinase interferes with host innate immune response by inhibiting the activation of IRF3. PloS one. 2011; 6:e16870.

29. Sen N, Sommer M, Che X, White K, Ruyechan WT and Arvin AM. Varicella-zoster virus immediate-early protein 62 blocks interferon regulatory factor 3 (IRF3) phosphorylation at key serine residues: a novel mechanism of IRF3 inhibition among herpesviruses. Journal of virology. 2010; 84:9240-9253.

30. Merideth MA, Gordon LB, Clauss S, Sachdev V, Smith AC, Perry MB, Brewer CC, Zalewski C, Kim HJ, Solomon B, Brooks BP, Gerber LH, Turner ML, et al. Phenotype and course of Hutchinson-Gilford progeria syndrome. The New 
England journal of medicine. 2008; 358:592-604.

31. McClintock D, Ratner D, Lokuge M, Owens DM, Gordon LB, Collins FS and Djabali K. The mutant form of lamin A that causes Hutchinson-Gilford progeria is a biomarker of cellular aging in human skin. PloS one. 2007; 2:e1269.

32. Roe K, Gibot S and Verma S. Triggering receptor expressed on myeloid cells-1 (TREM-1): a new player in antiviral immunity? Frontiers in microbiology. 2014; 5:627.

33. Concha M, Wang X, Cao S, Baddoo M, Fewell C, Lin Z, Hulme W, Hedges D, McBride J and Flemington EK. Identification of new viral genes and transcript isoforms during Epstein-Barr virus reactivation using RNA-Seq. Journal of virology. 2012; 86:1458-1467.

34. Metcalf TU, Cubas RA, Ghneim K, Cartwright MJ, Grevenynghe JV, Richner JM, Olagnier DP, Wilkinson PA, Cameron MJ, Park BS, Hiscott JB, Diamond MS, Wertheimer AM, et al. Global analyses revealed age-related alterations in innate immune responses after stimulation of pathogen recognition receptors. Aging cell. 2015; 14:421432.

35. Samuel MA and Diamond MS. Alpha/beta interferon protects against lethal West Nile virus infection by restricting cellular tropism and enhancing neuronal survival. Journal of virology. 2005; 79:13350-13361.

36. Rodier F, Coppe JP, Patil CK, Hoeijmakers WA, Munoz DP, Raza SR, Freund A, Campeau E, Davalos AR and Campisi J. Persistent DNA damage signalling triggers senescence-associated inflammatory cytokine secretion. Nature cell biology. 2009; 11:973-979.

37. Iwasa H, Han J and Ishikawa F. Mitogen-activated protein kinase p38 defines the common senescence-signalling pathway. Genes to cells : devoted to molecular \& cellular mechanisms. 2003; 8:131-144.

38. Li Q, Ali MA and Cohen JI. Insulin degrading enzyme is a cellular receptor mediating varicella-zoster virus infection and cell-to-cell spread. Cell. 2006; 127:305-316.

39. Abe T and Barber GN. Cytosolic-DNA-mediated, STINGdependent proinflammatory gene induction necessitates canonical NF-kappaB activation through TBK1. Journal of virology. 2014; 88:5328-5341.

40. Holm CK, Jensen SB, Jakobsen MR, Cheshenko N, Horan KA, Moeller HB, Gonzalez-Dosal R, Rasmussen $\mathrm{SB}$, Christensen MH, Yarovinsky TO, Rixon FJ, Herold BC, Fitzgerald KA, et al. Virus-cell fusion as a trigger of innate immunity dependent on the adaptor STING. Nature immunology. 2012; 13:737-743.

41. Nazmi A, Mukhopadhyay R, Dutta K and Basu A. STING mediates neuronal innate immune response following Japanese encephalitis virus infection. Scientific reports. 2012; 2:347.

42. Mitzel DN, Lowry V, Shirali AC, Liu Y and StoutDelgado HW. Age-enhanced endoplasmic reticulum stress contributes to increased Atg9A inhibition of STINGmediated IFN-beta production during Streptococcus pneumoniae infection. Journal of immunology. 2014; 192:4273-4283. 